\title{
Scales and structure of frontal adjustment and freshwater export in a region of fresh water influence
}

\author{
J. Hopkins · J.A. Polton
}

Received: date / Accepted: date

\begin{abstract}
Sea surface temperature satellite imagery and a regional hydrodynamic model are used to investigate the variability and structure of the Liverpool Bay thermohaline front. A statistically based water mass classification technique is used to locate the front in both data sets. The front moves between $5 \mathrm{~km}$ and $35 \mathrm{~km}$ in response to spring-neap changes in tidal mixing, an adjustment that is much greater than at other shelf-sea fronts. Superimposed on top of this fortnightly cycle are semi-diurnal movements of 5-10 $\mathrm{km}$ driven by flood and ebb tidal currents. Seasonal variability in the freshwater discharge and the density difference between buoyant inflow and more saline Irish Sea water give rise to two different dynamical regimes. During winter, when cold inflow reduces the buoyancy of the plume, a bottom-advected front develops. Over the summer, when warm river water provides additional buoyancy, a surface-advected plume detaches from the bottom and propagates much larger distances across the Bay. Decoupled from near-bed processes the position of the surface front is more variable.

Fortnightly stratification and re-mixing over large areas of Liverpool Bay is a potentially important mechanism by which fresh water, and its nutrient and pollutant loads, are exported from the coastal plume system. Based on length scales estimated from model and satellite data the erosion of post-neap stratification is estimated to be responsible for exporting approximately $19 \%$ of the fresh estuarine discharge annually entering the system. Although the baroclinic residual circulation makes a more significant contribution to fresh-
\end{abstract}

J. Hopkins

National Oceanography Centre, Joseph Proudman Building, 6 Brownlow Street, Liverpool, L3 5DA

Tel.: +44(0)151795 4800

E-mail: jeh200@noc.ac.uk

J.A. Polton

National Oceanography Centre, Joseph Proudman Building, 6 Brownlow Street, Liverpool, L3 5DA 
water fluxes the episodic nature of the spring-neap cycle may have important implications for biogeochemical cycles within the bay.

Keywords spring-neap $\cdot$ thermohaline front $\cdot$ freshwater export $\cdot$ stratification $\cdot$ coastal $\cdot$ shelf-sea

\section{Introduction}

Liverpool Bay is a Region of Fresh Water Influence (ROFI). Located in the southeastern corner of the Eastern Irish Sea (Fig. 1) the region receives on average 200-300 $\mathrm{m}^{3} \mathrm{~s}^{-1}$ of fresh water from the Mersey, Dee, Ribble and Clwyd river catchments. This input of buoyant river water creates an east-west density gradient of the order $5 \times 10^{-5} \mathrm{~kg} \cdot \mathrm{m}^{-4}$ (Palmer, 2009). Coupled with variable winds, a large tidal range and strong currents (up to $10 \mathrm{~m}$ and $1 \mathrm{~m} \cdot \mathrm{s}^{-1}$ at spring tides respectively), the dynamics of Liverpool Bay are complex (Polton et al, 2011). The strength and extent of stratification is governed by the competition between the stratifying influence of freshwater discharge injecting buoyancy into the system, and the de-stratifying effect of tidal and wind mixing. The system oscillates between episodes of well mixed conditions and times of periodic and enduring stratification (Sharples and Simpson, 1993, 1995; Simpson et al, 1990). Based on a potential energy formulation, Simpson et al (1990) explore the conditions necessary to maintain stratification against tidal mixing where stability is provided through two main processes: (a) the estuarine circulation driven by horizontal density gradients, and (b) vertical tidal shear straining the density field. The term ROFI was subsequently coined in a series of early 1990 papers by Simpson (e.g. Simpson et al (1990, 1991)). Burchard (2009) extends this analysis by including wind straining. The maximum extent of freshwater influence is marked by a thermohaline front running north-south across the bay, seaward of which the competition between surface heating and tidal stirring dominate the dynamics.

Most of the tidal variability in Liverpool Bay is accounted for by the semidiurnal lunar and solar tidal constituents, $\mathrm{M}_{2}$ and $\mathrm{S}_{2}$, with 12.4 and 12 hour periods respectively. A fortnightly spring-neap cycle results from the difference in speeds between these two constituents. Every two weeks the gravitational pull of the sun and moon are aligned and larger spring tides occur. In-between, during neap tides, the tidal range is smaller and currents are weaker. An elliptical semi-diurnal lunar constituent, $\mathrm{N}_{2}$, with a 12.65 hour period modulates the amplitude of consecutive spring and neap tides.

Enduring periods of stratification are observed to occur on fortnightly timescales following neap tides. These episodes are triggered by a reduction in tidal mixing energy coupled with an increase in stability and dampening of vertical mixing due to semi-diurnal tidal straining. This allows the density driven estuarine circulation to dominate and more permanent stratification to develop (Linden and Simpson, 1988b; Sharples and Simpson, 1993, 1995; Simpson et al, 1990). A stratified region, delimited by a strengthening surface front propagates westward, compensated at depth by onshore flows (Czitrom and 
Simpson, 1998; Sharples and Simpson, 1993). Isopycnals on the eastern side of the expanding stratified zone slope downwards forming a bottom-attached front. Waters inshore of this reattachment tend to remain vertically well mixed. Stratification may persist for several days following neap tides until increases in vertical mixing with the approaching springs re-mixes the water column. In addition to this fortnightly cycle, frontal movement occurs on semi-diurnal timescales; flood-ebb advection and tidal straining both alter the structure of the water column and position of the front.

Tidal variations in mixing intensity and stratification, and the associated changes in circulation modulate the horizontal flux and export of fresh water, suspended sediments, river pollutants and nutrients in estuarine and ROFI systems (Burchard et al, 2008; Jay and Musiak, 1994; Monismith et al, 1996; Prandle, 2004). It is therefore important to know the spatial and temporal scales of these adjustments. Spring-neap changes in tidal mixing, and the $\mathrm{N}_{2}$ modulation of this cycle, ebb-flood advection, tidal straining, the magnitude and direction of wind stress and the rate of fresh water input all contribute to the stability of the water column and propagation of the front. The strength of estuarine circulation during neap tides has been seen to increase in response to reduced tidal mixing (Geyer and Cannon, 1982; Geyer et al, 2000; Nunes and Lennon, 1987). Linden and Simpson (1988a) suggest that the salt flux during periods of prolonged stratification may be an order of magnitude greater than when increased turbulence maintains a well mixed water column. Additionally, semi-diurnal changes in stability caused by tidal straining can enhance shoreward near-bottom residual flows (Scully and Friedrichs, 2007). In a heavily populated area that is under pressure from industry, shipping and tourism understanding the export of fresh water and its nutrient and pollutant loads is important in the development of predictive models and coastal management tools.

In-situ observational data, much of which has been collected as part of the Irish Sea Observatory (ISO), provides a rich time series of measurements allowing evolution of the water column structure at one point to be studied. In this paper we use both remotely sensed sea surface temperature (SST) observations and model data to examine the spatial scales over which frontal adjustment may occur. This contributes to our understanding of Liverpool Bay by providing a more synoptic picture of the dynamics. The location of the front is estimated from satellite SST images using a statistical classification technique tailored specifically for this work. This analysis is supplemented and extended by output from POLCOMS (Proudman Oceanographic Laboratory Coastal Ocean Modelling System), a 3D hydrostatic sigma coordinate numerical model specifically designed to simulate macro-tidal regions, allowing changes in the vertical structure of the front to be examined. We aim to address the following questions: (1) What are the fortnightly and semi-diurnal scales of frontal movement caused by spring-neap and flood-ebb changes in tidal mixing? (2) What contribution do enduring periods of stratification and re-mixing make to the export of fresh water from the Liverpool Bay coastal plume system? 
Sections 2 and 3 describe the data sets used in our analysis and the water mass classification technique that has been developed. Sections 4 and 5 present our analysis of satellite and model data. In Section 6 we estimate the potential equivalent fresh water flux driven by the spring-neap tidal mixing cycle. Discussions and conclusions are presented in Section 7.

\section{Data}

Here we describe the data sets used in this study. The position of the front is estimated from both satellite SST observations and from a regional model. This analysis is supplemented and validated by in-situ observations collected as part of the Irish Sea Observatory.

\subsection{Satellite Sea Surface Temperature}

Satellite images of sea surface temperature (SST) between 2005 and 2009, at a spatial resolution of $1 \mathrm{~km}$, from the Advanced Very High Resolution Radiometer (AVHRR) have been used. Measurements from each overpass, rather than composite images were selected in order to maximize the size of the data set and to ensure that any semi-diurnal frontal movement could be resolved. Data was provided by the NERC Earth Observation Data Acquisition and Analysis Service, Plymouth (http://www.neodaas.ac.uk/).

\subsection{POLCOMS}

The model is configured on a $1.8 \mathrm{~km}$ (1 nautical mile) B-grid that covers the whole of the Irish Sea with 32 sigma depth levels. Temperature and salinity fronts are preserved using the Piecewise Parabolic Method (James, 1996) advection scheme and a quadratic drag momentum boundary condition is used at the bed (implemented in Holt and James (1999)). Following Ruddick et al (1995) the bottom drag coefficient, $C_{d}$, is given by $C_{d}=\left(\kappa / \ln \left(z / z_{0}\right)\right)^{2}$, where $\kappa$ is the von Kármán constant, $z_{0}=0.005 \mathrm{~m}$ is the bed roughness length and $z$ is the height above the bed. If $C_{d}$ is less than 0.005 , it is assumed to be 0.005 . Vertical mixing is parameterised using the Canuto et al (2001) k-epsilon scheme. The tuneable coefficients are presented in Holt and Umlauf (2008), wherein its performance against other turbulence closure schemes is also reported.

The model is forced by sea surface elevation and depth varying tidal currents at the open boundaries. These data are taken from the Atlantic Margin Model (12 km resolution) which covers the North West European Shelf and encapsulates the shelf break. This in turn is forced by the UK Met. Office's $1 / 3$ degree Forecast Ocean Assimilation Model (FOAM). The high resolution Irish Sea simulation, in this study, is forced with 6 hourly, 1 degree, ECMWF (European Centre for Medium-Range Weather Forecasts) winds and surface fluxes 
that are computed from meteorological bulk formulae. Therefore mesoscale meteorological effects are excluded from these simulations.

River discharges, forcing the simulation, are computed from daily Environment Agency river gauge measurements. Conversion factors to scale the river flows into estuarine discharge fluxes come from the Centre for Ecology and Hydrology (CEH, 2007; CEH, pe. comms.). Outside of Liverpool Bay climatological daily values are used, though in the bay the actual daily river discharges are used. These are computed from the 13 gauges between the Clwyd and the Ribble estuaries (Fig. 1).

River temperatures are set to vary with an annual sinusoidal cycle. This seasonal cycle is the first mode of variability from 3 years of SST data at the mouth of the Mersey. These data are measured by the Liverpool Viking Ferry as it passes through the Mersey Narrows (Balfour et al, 2007). Similarly the freshwater discharge was set to a constant value of 10 psu to better represent the observed Ferry based salinities in the Mersey Narrows.

The model is spun up from a climatological state for two years and analysis is taken from 2007. For more details about the POLCOMS hydrodynamics refer to Holt and James (2001) and Holt et al (2005). For specific examples of model configurations at this resolution see Holt and James (2006) and Holt and Proctor (2008). Further model validation and comparisons against observational data for Liverpool Bay can found in Polton et al (2011) and Howarth and Palmer (2011).

\subsection{Irish Sea Observatory time series}

Fixed point time series measurements of temperature, salinity and vertical current structure were obtained from the main ISO mooring site (Fig. 1) at the Mersey Bar $\left(53^{\circ} 32^{\prime} \mathrm{N}, 3^{\circ} 21.8^{\prime} \mathrm{W}\right)$. Conductivity and temperature (CT) sensors are located in a frame on the seabed, and at 5 and $10 \mathrm{~m}$ below the sea surface, logging 10-min averages. CT sensors logging every 30 -mins are also located at $1 \mathrm{~m}$ below the sea surface on a CEFAS SmartBuoy. An upward looking RDI 600-kHz Acoustic Doppler Current Profiler (ADCP) mounted on the bed frame records currents in 10-min ensembles over $1 \mathrm{~m}$ depth bins. Every 4-6 weeks these instruments are serviced and a CTD grid of 35 fixed stations is completed. Density was calculated from Practical Salinity (PSS78) using the International Equation of State of Sea Water, 1980 (Unesco, 1981). Details on the Irish Sea Coastal Observatory and the above time series of measurements can be found in Howarth and Palmer (2011).

\section{Methods: water mass classification}

The river water that enters Liverpool Bay has different thermohaline characteristics to the Irish Sea water further offshore. The greater thermal inertia of the ocean ensures that, aside from always being fresher, river discharge is 
warmer than sea water in the summer, and colder in the winter. As demonstrated in Fig. 2, this allows the freshwater plume to be identified year round from satellite images of SST. Periods around the spring and autumn equinoxes where ocean-estuarine temperature differences are smallest are times when identification of the front is more difficult (Fig. 2c).

Here, a statistical technique know as mixture modelling, that enables a set of observed data to be divided into different subsamples, is used to separate observations of SST into two different surface water masses. The division between them is assumed to be a reliable estimate of the position of the front. The technique is also applied to modelled longitude-depth transects of density extending westward from Formby Point (Fig. 1). In this way our analysis is supplemented by information on the vertical structure of the plume. Statistical approaches to automated classification and edge discrimination have been explored in an oceanographic context by a number of authors: Cayula and Cornillon (1992), Miller (2009) and Shimada et al (2005) to name but a few. In the following sections the statistical methodology and a validation of the technique are presented.

\subsection{Statistical methodology}

For a set of observations $\mathbf{x}=\left\{x_{1}, x_{2}, \ldots, x_{n}\right\}$, which in our analysis are either temperature or density, suppose that there are $K$ different water masses within that set. For our purposes $K$ is set to either 1 or 2 (the selection of which will be discussed later), since we are either able to distinguish two water masses and therefore a front $(K=2)$, or only one water mass and no front $(K=1)$. For each water mass, $k=1, \ldots, K$, the observations can be parameterized by a Gaussian distribution with mean $\boldsymbol{\mu}_{k}$ and covariance matrix $\boldsymbol{\Sigma}_{k}$. Note that alternative distributions could be used if necessary. The Gaussian probability density of water mass $k$ is therefore:

$$
\begin{aligned}
f_{k}(x) & =\phi\left(x \mid \boldsymbol{\mu}_{k}, \boldsymbol{\Sigma}_{k}\right) \\
& =\frac{1}{(2 \pi)^{\frac{1}{2}}\left|\boldsymbol{\Sigma}_{k}\right|^{\frac{1}{2}}} \exp \left(-\frac{1}{2}\left(x-\boldsymbol{\mu}_{k}\right)^{t}\left(\boldsymbol{\Sigma}_{k}\right)^{-1}\left(x-\boldsymbol{\mu}_{k}\right)\right),
\end{aligned}
$$

where superscripts ${ }^{t}$ and ${ }^{-1}$ denote the matrix transpose and inverse respectively. The relative importance of each water mass $k$ within the set of observations as a whole is expressed by a prior probability or weight $\mathbf{a}_{k}$ i.e. the proportion of the total number of observations assigned to each water mass. The $k$-component Gaussian mixture model is then a weighted linear combination of the $K$ probability density functions:

$$
f(x)=\sum_{k=1}^{K} \mathbf{a}_{k} f_{k}(x)=\sum_{k=1}^{K} \mathbf{a}_{k} \phi\left(x \mid \boldsymbol{\mu}_{k}, \boldsymbol{\Sigma}_{k}\right) .
$$


The log-likelihood of observations $\mathbf{x}$ given parameters $\theta=\left\{\mathbf{a}_{k}, \boldsymbol{\mu}_{k}, \boldsymbol{\Sigma}_{k}\right\}$ is expressed as:

$$
L(\mathbf{x} \mid \theta)=\sum_{i=1}^{n} \log \left(\sum_{k=1}^{K} \mathbf{a}_{k} \phi\left(x_{i} \mid \boldsymbol{\mu}_{k}, \boldsymbol{\Sigma}_{k}\right)\right) .
$$

The unknown parameters are estimated using the Expectation-Maximization (EM) algorithm that aims to maximize the $\log$-likelihood $L(\mathbf{x} \mid \theta)$. The weights $\mathbf{a}_{k}$ and the Gaussian parameters $\boldsymbol{\mu}_{k}$ and $\boldsymbol{\Sigma}_{k}$ can be optimized separately over four steps where parameters estimated at the $p^{t h}$ and $(p+1)^{t h}$ iterations are marked ${ }^{(p)}$ and ${ }^{(p+1)}$ respectively. These steps are as follows:

1. Select starting values for the iterations using a $k$-means clustering technique (discussed later)

2. Compute posterior probabilities, $P_{i, k}$, for all $i=1, \ldots, n$ and $k=1, \ldots, K$. The posterior probability is a revised probability that takes into account the most up to date information about $\mathbf{a}_{k}, \boldsymbol{\mu}_{k}$ and $\boldsymbol{\Sigma}_{k}$ calculated during the previous iteration. When $p=1$ these will be the starting values from step 1 .

$$
P_{i, k}=\frac{\mathbf{a}_{k}^{(p)} \phi\left(x_{i} \mid \boldsymbol{\mu}_{k}^{(p)}, \boldsymbol{\Sigma}_{k}^{(p)}\right)}{\sum_{k=1}^{K} \mathbf{a}_{k}^{(p)} \phi\left(x_{i} \mid \boldsymbol{\mu}_{k}^{(p)}, \boldsymbol{\Sigma}_{k}^{(p)}\right)} .
$$

3. Optimize the Gaussian parameters, $\boldsymbol{\mu}_{k}$ and $\boldsymbol{\Sigma}_{k}$, and prior probabilities $\mathbf{a}_{k}$ using $P_{i, k}$.

$$
\begin{gathered}
\mathbf{a}_{k}^{(p+1)}=\frac{\sum_{i=1}^{n} P_{i, k}}{n}, \\
\boldsymbol{\mu}_{k}^{(p+1)}=\frac{\sum_{i=1}^{n} P_{i, k} x_{i}}{\sum_{i=1}^{n} P_{i, k}} \\
\boldsymbol{\Sigma}_{k}^{(p+1)}=\frac{\sum_{i=1}^{n} P_{i, k}\left(x_{i}-\boldsymbol{\mu}_{k}^{(p+1)}\right)\left(x_{i}-\boldsymbol{\mu}_{k}^{(p+1)}\right)^{t}}{\sum_{i=1}^{n} P_{i, k}}
\end{gathered}
$$

4. Compute the log-likelihood using the most up to date parameter estimates.

$$
L(\mathbf{x} \mid \theta)^{(p+1)}=\sum_{i=1}^{n} \sum_{k=1}^{K} P_{i, k} \log \mathbf{a}_{k}^{(p+1)}+\sum_{i=1}^{n} \sum_{k=1}^{K} P_{i, k} \log \phi\left(x_{i} \mid \boldsymbol{\mu}_{k}^{(p+1)}, \boldsymbol{\Sigma}_{k}^{(p+1)}\right) .
$$

Steps 2 and 3 are repeated until the parameter values and likelihood have converged. The convergence tolerance for the log-likelihood function, $L(\mathbf{x} \mid \theta)$, and parameter values $\theta$, was set at $1 \times 10^{-3}$. A maximum of 100 iterations was allowed. Each observation $x_{i}$ is assigned to the water mass corresponding 
to the highest posterior probability $P_{i, k}$. In the first instance, observations of surface water temperature from the CEFAS SmartBuoy are used to determine which cluster represents the fresher river discharge. If an in-situ measurement was not available within 12 hours of the satellite overpass then the expected seasonal horizontal temperature gradient and location of each water mass was used to identify the plume. This was necessary for 35 images between $28^{\text {th }}$ October and $10^{\text {th }}$ December 2008 and for 26 images in September 2009 when no SmartBuoy data was available.

The EM algorithm is initiated (step 1 above) with a first guess at optimal parameter values generated by a $k$-means clustering technique. This aims to partition the $n$ observations into $k$ water masses such that each observation belongs to the water mass with the nearest mean. For $K$ water masses with means $Z=\left\{z_{1}, \ldots, z_{k}\right\}$ the total mean squared error, denoted $C$, between the observation and the representative water mass mean is minimsed.

$$
C(Z, \eta)=\sum_{i=1}^{n}\left\|x_{i}-Z_{\eta(i)}\right\|^{2},
$$

where $\eta(i)=k$ denotes assignment of observation $x_{i}$ to the $k^{t h}$ water mass. The problem is solved iteratively by assigning each observation to its closest water mass using Euclidean distance, and then updating the mean by computing the average of all samples assigned to it.

The value of $K$, the optimal number of water masses or clusters that the set of observations $\mathbf{x}$ should be divided into is itself an unknown quantity. It is determined by a scoring system known as Akaike's Information Criterion (AIC), a measure of statistical model fit (Hastie et al, 2001). It attempts to find the minimum model fit that correctly explains the data by examining the complexity of the model, i.e. the number of water masses, together with its goodness-of-fit to the data. $\operatorname{AIC}(K)=-2 \log L_{K}$, where $L_{K}$ is the value of the maximum likelihood using $K$ clusters. For each set of observations $\mathbf{x}$ the AIC for $K=1$ and $K=2$ is calculated. The value of $K$ that generates the lowest AIC is taken as the optimal number of clusters with which to subdivide $\mathbf{x}$ into. If $K=1$ then only one water mass can be distinguished and the temperature histogram is described as unimodal (Fig. 3a). When $K=2, \mathbf{x}$ is best divided into two different populations and the distribution of temperatures is bimodal (Fig. 3b).

Owing to variable cloud cover extent not all available SST images between 2005 and 2009 were analyzed. Selection was based on the percentage and distribution of observations available within the area south of $54.42^{\circ} \mathrm{N}$ and east of $4.9^{\circ} \mathrm{W}$ (marked in Fig. 1). A minimum requirement for $30 \%$ of the area to contain SST observations, and of these $15 \%$ to be east of $3.6^{\circ} \mathrm{W}$ was set. This was to ensure that enough measurements both offshore and nearshore were available to estimate the position of any front in the area. In total 1286 images between 2005 and 2009 met these criteria. 
3.2 Quality control

To maintain only the highest quality results, classifications were discarded if an optimization did not converge; if only one water mass could be identified (minimum $\mathrm{AIC}(\mathrm{K})=1$ ); or if a water mass was assigned less than $5 \%$ of the available data. To further ensure the identification of two well defined watermasses, particularly during equinox periods, and preserve only the most reliable estimates of frontal location the internal $\left(V_{\text {int }}\right)$ and external $\left(V_{\text {ext }}\right)$ variances of the two water masses were calculated. $V_{i n t}$ is the sum of the variances within each of the watermasses. $V_{\text {ext }}$ is the contribution to the total variance $\left(V_{t o t}\right)$ of all the obervations resulting from the separation, where $V_{t o t}=V_{i n t}+V_{\text {ext }}$. As the proportion that $V_{\text {ext }}$ contributes to $V_{t o t}$ increases so the definition between the two populations is enhanced. $\frac{V_{e x t}}{V_{t o t}}$ is therefore used as an indicator of watermass definition. If $\frac{V_{e x t}}{V_{t o t}}<0.3$ the two watermasses are considered to be weakly defined. 92 image classifications were rejected on this basis, the majority during equinox periods (March-April and SeptemberOctober), when estuarine and oceanic water temperatures are most similar and there is an absence of vertical temperature variations (Czitrom and Simpson, 1998). Additionally, 6 classifications were rejected on account of the water mass temperature differences $\left(\left|\mu_{1}-\mu_{2}\right|\right)$ being $1.5^{\circ} \mathrm{C}$ greater than the harmonically fitted seasonal value. Water mass statistics falling outside reasonable bounds on the expected seasonal values are likely to result in unrealistic estimates of frontal location.

Out of the 1286 images analysed, 125 were rejected according to the above criteria. Between 209 and 286 images were available for each of the 5 years. An equal number of images were available during each season; 579 in the summer (April-September) and 582 in the winter (October-March). In general observations are well distributed between months. Figure 6 shows the temporal spread of observations over each year.

\subsection{Validation of technique}

Irish Sea Observatory CTD surveys of Liverpool Bay allow the results of this technique to be validated. Fig. 4 shows the position of the front estimated from the SST in a single overpass on $20^{\text {th }}$ June 2007 at 21:40:00, and CTD transects of the temperature taken between the $20^{\text {th }}$ and $21^{\text {st }}$ June 2007 . The position of each CTD cast has been corrected for barotropic tidal displacement relative to the time of the satellite image using POLCOMS. The position of the front estimated from analysis of the SST image is not just a surface skin phenomenon, but a genuine water mass boundary. The location of the front in Fig. 4a is comparable to the surface outcropping of the $13.45^{\circ} \mathrm{C}$ isotherm in the CTD transects (Fig. 4b).

Salinity rather than temperature however is the primary control on density structures within Liverpool Bay (Palmer, 2009). Consequently, model density rather than temperature is used to identify the location of the front. Fig. 5 
shows model output of temperature, salinity and density corresponding to the same date and time as Fig. 4. The freshwater signature of the plume, as shown by the salinity field in Fig. 5c, does not extend as far offshore as suggested by analysis of the SST field alone (Fig. 5b). Therefore, estimating the position of the surface and bottom fronts using longitude-depth transects of density provides more physically realistic results (Fig. 5d).

\section{Scales of frontal adjustment from SST images}

In this section analysis of the SST images is used to consider both the springneap and semi-diurnal variability of the Liverpool Bay front. The median position (longitude) of the front between $53.5^{\circ} \mathrm{N}$ and $54^{\circ} \mathrm{N}$ for all images analyzed is presented in Fig. 6 . There is a large amount of variability within and between days, months and seasons. Estimates of the position range from $3.15^{\circ} \mathrm{W}$ to $4.5^{\circ} \mathrm{W}$.

Any spring-neap adjustment is difficult to distinguish because of semidiurnal flood-ebb advection, the impact of variable wind stress and river discharge, and a sparsity of data over individual fortnightly periods. Furthermore, as can be seen in Figs. 8 and 9 the front tends to be orientated NW-SE such that if the northern half of the area were to be obscured by clouds then the median position of the front across the bay would be biased toward the east, and vice versa.

\subsection{Spring-neap movement}

To assess whether there is any spring-neap variability a more composite presentation of results is necessary where semi-diurnal movement and the affects of winds and river input can be averaged out. Results are therefore subdivided according to the 14 day spring-neap cycle. As clarification, Fig. 7 shows the median top to bottom density difference $\left(\Delta \rho \mathrm{kg} \cdot \mathrm{m}^{-3}\right)$ at the main observatory mooring site over one year, averaged according to the day of the spring-neap cycle, and the mean high water level near the mouth of the Mersey calculated for the equivalent periods. The highest tidal range and therefore the strongest spring currents occur on the third day. Neap tides occur on day ten. Even from this long term mean a fortnightly variation in the strength of stratification can be seen. The median value of $\Delta \rho$ is weakest during spring tides $\left(<0.2 \mathrm{~kg} \cdot \mathrm{m}^{-3}\right)$, and strongest $\left(0.6 \mathrm{~kg} . \mathrm{m}^{-3}\right)$ one day after neaps (day 11$)$. The wide range of values for each day highlights that each event will be different, but the overall trend demonstrates that the spring-neap cycle is persistent enough to show up in long term averages.

Using this approach, all the SST images are sorted according to their position in the spring-neap cycle, and the percentage of time that waters were classified as being part of the coastal plume calculated. Subsequently, in the absence of any other statistics, we assume that there is a 50-50 chance $(p>=0.5)$ 
of any pixel being classified as either water mass, and calculate confidence intervals. Fig. 8 summarizes the results for spring (days 3-4) and neap (days 10-11) periods. The thick contours mark the $99 \%$ one-sided confidence interval that $p>=0.5$, and represent the position shoreward of which there is a significant bias towards plume waters. In contrast the $1 \%$ contours (dashed lines) mark the lowest confidence level. The shaded areas in between represent the most probable region for the front to be found in during neap and spring periods.

During the summer, warmer surface waters are observed further west during periods of weaker neap tidal currents (Fig. 8a). The contrast is strongest between $53.5^{\circ} \mathrm{N}$ and $53.6^{\circ} \mathrm{N}$ where, based on the $99 \%$ contour, the front is located between $3.4-3.5^{\circ} \mathrm{W}$ during springs and near $3.9^{\circ} \mathrm{W}$ at neaps. During the summer therefore $25-30 \mathrm{~km}$ of movement in the thermal surface expression of the front can occur. Throughout the winter (Fig. 8b), the difference between the $99 \%$ spring and neap contours is greatly reduced to $5-10 \mathrm{~km}$. Additionally, in contrast to the summer, the neap fronts are more likely to be observed further inshore. With the exception of summertime neaps the front is orientated northwest-southeast.

The distance between the $99 \%$ and $1 \%$ contours indicates the variability in position of the front owing to flood-ebb advection, wind mixing, and river discharge. These distances are of the same order of magnitude as any adjustments resulting from fortnighly variability in tidal mixing energy. This variability is slighly higher during the summer.

\subsection{Semi-diurnal movement}

The movement resulting from flood-ebb advection is explored in Fig. 9 where 14 clear overpasses were available over a 48 hour period in February 2008. During the winter there is minimal surface skin heating and no seasonal thermal stratification making this an ideal period of time to resolve daily frontal adjustment. The depth-mean east-west flows $\left( \pm \mathbf{u} \mathrm{m} . \mathrm{s}^{-1}\right)$ have been calculated from the ADCP at the main observatory mooring site and are representative of the rectilinear tidal currents across Liverpool Bay. In this example there is $5-10 \mathrm{~km}$ of movement over a flood-ebb cycle and offshore displacement of the front with increasing latitude. Comparison of the fronts' location to the state of the tide shows the front moving shoreward during flood and seaward during ebb. The greatest westward and eastward positions tend to occur around high and low water slack periods. Similar scales of adjustment are seen at other times (e.g. $2^{\text {nd }}$ May 2007 and $22^{\text {nd }}-23^{\text {rd }}$ January 2007) when enough cloud free overpasses are available.

\section{Modeled frontal movement and structures}

In this section we present an analysis of hourly model density along an eastwest transect extending offshore from Formby Point (Fig. 1). This high res- 
olution model data enables individual spring-neap events and semi-diurnal movement to be better resolved. Depth-longitude transects also allow the vertical structure of the front to be considered. Satellite SST images only permit an estimate of the surface position of the front, whereas simultaneously locating the bottom reattachment from model transects enables an estimate of the extent of stratification. Furthermore, other important factors that complicate the control of tidal mixing can be assessed: seasonal variations in horizontal and vertical temperature gradients, river discharge and wind mixing.

There is a fortnightly cycle in the advance and retreat of the front (Fig. 10a), and in the extent of stratification (Fig. 10b). In general, the front is located furthest offshore approximately 1-2 days after neap tides. The bottom front is located around $3.3^{\circ} \mathrm{W}$. It migrates no further east than $3.2^{\circ} \mathrm{W}$, and no further seaward of $3.5^{\circ} \mathrm{W}$. In contrast, the surface expression moves much greater distances. During periods of more enduring stratification, around neap tides, it is often found between $3.5^{\circ} \mathrm{W}$ and $3.8^{\circ} \mathrm{W}$. This translates to between $10 \mathrm{~km}$ and $35 \mathrm{~km}$ of fortnightly movement.

There is some evidence over the warmer months that the fronts' development is influenced by $\mathrm{N}_{2}$ modulation of the spring-neap cycle. The maximum position of the surface front on days $75,88,104,119$ and 149 (black circles in Fig. 10a), when the range in tidal mixing between spring and neap tides is large, reaches or exceeds $3.55^{\circ} \mathrm{W}$ ( $\geq 15 \mathrm{~km}$ stratified). In contrast, during the following period where the tidal stirring during neap tides is greater, frontal movement is reduced. On days 174, 193, 206 and 221 (black triangles in Fig. 10a), the surface expression outcrops closer to the shore and a reduced area of the bay stratifies. The front reaches its furthest westward extent $\left(3.8^{\circ} \mathrm{W}\right)$ around day 236 following a very weak neap tide.

Fortnightly variation in tidal mixing is not the only control on frontogenesis in Liverpool Bay, and the magnitude of frontal adjustment varies throughout the year. Fig. 11 summarizes the horizontal and vertical anomalies in temperature, salinity and density; the variation in tidal and wind mixing; and the discharge of fresh water. The tidal mixing at $3.4^{\circ} \mathrm{W}\left(\varphi_{\text {tide }}\right)$, and the wind mixing over the area $\left(\varphi_{\text {wind }}\right)$ are calculated from $\epsilon \kappa_{b} \rho\left\langle\mathbf{u}^{3}\right\rangle$ and $\delta \kappa_{s} \rho_{a} W_{s}^{3}$ respectively. $\left\langle\mathbf{u}^{3}\right\rangle$ is the depth mean amplitude of the rectilinear tidal stream at $3.4^{\circ} \mathrm{W}$, cubed and averaged over a tidal cycle. $W_{s}$ is the near surface wind speed. $\epsilon=0.003$ and $\delta=0.023$ are the tidal and wind mixing efficiencies respectively (Simpson and Bowers, 1981). $\kappa_{b}=0.003$ and $\kappa_{s}=6.4 \times 10^{-5}$ are the bottom and surface drag coefficients associated with $\mathbf{u}$ and $W_{s} . \rho_{a}=1.3$ $\mathrm{kg} \cdot \mathrm{m}^{-3}$ and $\rho=1025 \mathrm{~kg} \cdot \mathrm{m}^{-3}$ are the approximate densities of air and sea water.

Based on this additional information three different 'regimes' are identified: (1) April to mid-September, (2) mid-September to mid-January, and (3) midJanuary to March. The main features of each of these 'regimes' will now be described and the details of specific fortnightly events within them looked at more closely. 


\section{1 'Regime' 1: surface-advected fronts}

The greatest and most consistent frontal response to weak neap tidal mixing takes place between April and mid-September ('regime' 1). Over this period wind mixing is generally weak (Fig. 11c), and both the vertical and horizontal gradients in temperature (Fig. 11e and f) indicate that warm river discharge is providing positive buoyancy to the fresh water plume. Coupled with a large input of fresh water between days 160 and 210 (Fig. 11d), all the important factors controlling frontogenesis are conducive to maximum surface advection of the fresh water plume (Fig. 10), and the onset of enduring stratification. At $3.4^{\circ} \mathrm{W}$ the top-bottom density difference is frequently $>2 \mathrm{~kg} \cdot \mathrm{m}^{-3}$ (Fig. 11a). As discussed previously it is during this period that the influence of $\mathrm{N}_{2}$ modulation on the spring-neap cycle can be most clearly seen.

Over days 184-197, despite high river discharges $\left(200-600 \mathrm{~m}^{3} \cdot \mathrm{s}^{-1}\right)$, the surface front does not progress further than $3.6^{\circ} \mathrm{W}$ (Fig. 12b), and the stratified zone between the top and bottom fronts does not exceed $15 \mathrm{~km}$. In contrast, over days 229-242, when discharge is low $\left(50 \mathrm{~m}^{3} \cdot \mathrm{s}^{-1}\right)$, the front moves beyond $3.8^{\circ} \mathrm{W}$ and stratification develops over a distance of $35 \mathrm{~km}$ (Figs. 12a and $10 \mathrm{~b})$. The principal difference between these two events is the tidal mixing; the range in mixing between spring and neaps tides is more than twice as large during event A (days 227-235), and the mixing energy available during neaps is a factor of six smaller. In addition to westward progression of the front, the bottom attached front retreats shoreward approximately $10 \mathrm{~km}$ during the neap period (Fig. 12a).

The scale of semi-diurnal frontal movement in response to flood-ebb tidal advection can be seen in Figs. 12a and 12b. Excursions of the surface front $(\sim 10 \mathrm{~km})$ are larger than the bottom reattachment $(<10 \mathrm{~km})$. During event $\mathrm{B}$ this movement is comparable to the fronts spring-neap adjustment.

\section{2 'Regime' 2: bottom-advected fronts}

Behaviour of the front between mid-September and mid-January ('regime' 2) is very different. In general, the top and bottom fronts remain locked together and respond to changes in tidal mixing in tandem. Between days 313 and 321 they reach $3.45^{\circ} \mathrm{W}$ (Fig. 12c), but the water column does not stratify. With the exception of a weak peak on day 325 of $0.5 \mathrm{~kg} . \mathrm{m}^{-3}, \Delta \rho$ remains below 0.25 kg. $\mathrm{m}^{-3}$ (Fig. 11a).

Over this autumn and winter period wind mixing is moderate-strong and the temperature of the river discharge makes a negative contribution to the plumes buoyancy. River water, that is up to $4^{\circ} \mathrm{C}$ colder than the sea water that it meets (Fig. 11f), reduces the net buoyancy of the plume to the point where it becomes convectively unstable $(+\Delta t$ in Fig. $11 \mathrm{e})$. The result is a bottom advected plume that tends to be well mixed, or occasionally weakly stratified. The scale of flood-ebb advection $(5-10 \mathrm{~km})$ during this period is of a similar magnitude to spring-neap adjustments (Fig. 12c). 


\section{3 'Regime' 3}

'Regime' 3 is distinguished from the surface-advected fronts in 'regime' 1 because the negative buoyancy contributions from the cold fresh water act to inhibit decoupling of the top and bottom fronts. Progression of the surface front to $3.7^{\circ} \mathrm{W}$ over days 22-28 (Fig. 12d) is the result of a sudden decrease in wind mixing and the preceding prolonged period of high discharge introducing sufficient volumes of fresh water to promote stratification, despite the destabilising temperature gradients. The initial advance of the surface front coincides with spring tidal currents. Large semi-diurnal movement of up to 20 $\mathrm{km}$ takes place over this period.

\section{Equivalent freshwater 'export'}

The stratification of large areas in Liverpool Bay, for a number of days following neap tides, and the subsequent erosion of this surface layer is a potential means of removing freshwater and its nutrient and pollutant load from the coastal plume system. Here we make a first attempt at estimating an equivalent fresh water flux resulting from these events.

Consider an $X Y \mathrm{~m}^{2}$ surface area of water, $h$ meters deep, that stratifies during neap tides. The surface and bottom layers are $h_{2}$ and $h_{1}$ meters thick respectively (Fig. 13). The bottom layer has the salinity of sea water, $S_{1}$. The fresher top layer has a lower salinity of $S_{2}$ which is considered to be a mixture of a volume $V_{f}$ of fresh water with salinity $S_{f}$, and a volume $V_{s w}$ of sea water of salinity $S_{s w}=S_{1}$ such that,

$$
S_{2}=\frac{S_{s w} V_{s w}+S_{f} V_{f}}{V_{s w}+V_{f}},
$$

where $V_{2}=V_{s w}+V_{f} . S_{1}$ and $S_{2}$ are set at 34 and 32 respectively, based on observational and model data. A salinity of 10 is chosen for the fresh water $S_{f}$ since this is the salinity of estuarine water input into the model. We are interested in the volume of fresh water $V_{f}$ required to freshen the top layer to $S_{2}$. This can then be considered as an equivalent volume flux of fresh water mixed out of the plume system when stratification is broken down. If layers 1 and $2 \mathrm{mix}$, and salt is conserved, then the total volume $V_{m i x}=X Y h$ has a new salinity of $S_{m i x}$ where,

$$
S_{m i x}=\frac{S_{1} V_{1}+S_{s w} V_{s w}+S_{f} V_{f}}{V_{m i x}} .
$$

Knowing that $V_{s w}=V_{2}-V_{f}$, substituting into Eqn. 11, and rearranging for $V_{f}$, the volume of fresh water needed to freshen the top layer is:

$$
V_{f}=\frac{S_{m i x} V_{m i x}-S_{1} V_{1}-S_{s w} V_{2}}{S_{f}-S_{s w}} .
$$


Setting $h_{2}=5 \mathrm{~m}$ and $h_{1}=20 \mathrm{~m}$, realistic values for the top and bottom layer depths respectively, and considering a conservative frontal adjustment of $X=10 \mathrm{~km}$ (Fig. 10), over a length scale of $Y=20 \mathrm{~km}, 8.3 \times 10^{7} \mathrm{~m}^{3}$ of fresh estuarine input $\left(S_{f}=10\right)$ is mixed out of the surface when this stratified zone is eroded.

Fig. 10 shows that this fortnightly cycle takes place for $\frac{2}{3}$ of the year $(\sim 17$ events), predominantly during the spring and summer. Therefore, spring-neap frontal adjustments of this size account for an equivalent freshwater export of $1.4 \times 10^{9} \mathrm{~m}^{3} \mathrm{yr}^{-1}$. Given that cumulatively over the year POLCOMS injects $7.3 \times 10^{9} \mathrm{~m}^{3}$ of $10 \mathrm{psu}$ water into the region from the four catchment basins this export accounts for approximately $19 \%$ of the total estuarine discharge. Movement of up to $35 \mathrm{~km}$ is possible so this fraction is a conservative estimate.

Within each estuary feeding into Liverpool Bay, the salinity field has a gradual along-channel gradient, from oceanic to fresh, as inflowing sea water at depth is continually freshened by vertical turbulent mixing with outflowing fresh water above. The choice of $S_{f}$ therefore determines what the equivalent volume flux $V_{f}$ relates to. Here, we have selected a salinity of 10 , to allow a comparison with the model, and $V_{f}$ relates to a volume of estuarine discharge, with a salinity that is a mixture of fresh river water and sea water. Recalculating using $S_{f}=0$ results in an equivalent volume of $5.9 \times 10^{7} \mathrm{~m}^{3}$ of pure fresh water being exported during each event. Taking $S_{f}$ up to a value of 20 does not change the order of magnitude of $V_{f}$ and our overall conclusion, that spring-neap cycles of stratification and re-mixing can remove significant volumes of fresh water from the coastal plume, remains the same.

\section{Discussion and conclusions}

Satellite SST images and model data reveal the position of the Liverpool Bay front to be highly variable across a range of timescales. Over a spring-neap cycle it can move between $5 \mathrm{~km}$ and $35 \mathrm{~km}$. On shorter, semi-diurnal timescales flood-ebb advection accounts for $5-10 \mathrm{~km}$ of movement, which is comparable to the lower range of spring-neap displacements. The fortnightly adjustments shown here are much greater than those observed at other shelf-sea fronts on the UK continental shelf where the dynamics are principally controlled by the competition between tidal mixing and surface heating. Based on infra-red satellite imagery of the Celtic Sea, Western Irish Sea and Islay fronts, where buoyancy added through surface heating is relatively constant throughout the summer, only a small $\sim 4 \mathrm{~km}$ adjustment in frontal position is attributed to the spring-neap stirring cycle (Simpson and Bowers, 1981). In contrast, episodic injections of fresh water into Liverpool Bay and seasonally varying density anomalies introduce a high degree of variability to the buoyancy and subsequently to the fronts' position. Liverpool Bay is also a lot shallower $(<50 \mathrm{~m})$ than the Celtic and Western Irish Sea, consequently, as previously highlighted by other authors (Burchard, 2009; Verspecht et al, 2009a), wind mixing plays an important role in controlling the strength, extent and timing of stratifi- 
cation, and can impose a more irregular behaviour. Bottom up mixing from tidal currents that can reach the sea surface also becomes a consideration in shallower waters.

The $\mathrm{N}_{2}$ cycle can limit westward propagation of the front and the area of Liverpool Bay that stratifies following neap tides. Contrasting the fronts response during the strongest neap tide (Fig. 12b), with one of the weakest (Fig.12a) demonstrates that the surface expression can move 2-3 times further during sufficiently weak tidal stirring. This is supported by other observational and model data that show $\mathrm{N}_{2}$ modulation of the spring-neap cycle to have an important control on post-neap stratification (Sharples and Simpson, 1995).

An estimate of the position of the Liverpool Bay front can be found in Vincent et al (2004) which is in broad agreement with the $99 \%$ confidence contours of Fig. 8, particularly during the winter. The westward increase in position with distance north is also a feature of Vincent et al (2004) and is consistent with northwesterly advection by surface residual currents (Verspecht et al, 2009b).

Tracking of the surface and bottom fronts in POLCOMS has revealed the Liverpool Bay freshwater plume to have two different dynamical regimes. During the winter a bottom-advected plume is most common ('regime' 2), where buoyant inflow is well mixed throughout the water column and the surface and bottom fronts lie on top of one another. During the summer ('regime' 1), river discharge initially spreads offshore maintaining contact with the bottom out to approximately $3.3^{\circ} \mathrm{W}$, beyond which point the upper part of the plume detaches from the bottom and spreads seaward as a surface advected front. The volume of river discharge and seasonal density anomalies appear to be the primary controls on plume structure. This is supported by Yankovsky and Chapman (1997) who predict the vertical structure and offshore spreading of buoyant plumes based solely on inflow parameters (including inflow velocity and density anomaly). Surface-advected plumes and the development of stratification is not strictly a summer regime. Where the volume of fresh water input is sufficient to offset the negative buoyancy contribution from the temperature a surface-advected plume may develop in the winter. Further evidence for winter stratification, in spite of destabilizing temperature gradients, is found in Sharples and Simpson (1995) and Czitrom and Simpson (1998).

Yankovsky and Chapman (1997), and references therein, help explain some of the features of results presented here. The front of a bottom-advected plume is established by offshore advection of buoyancy in the bottom boundary layer and continues to be pushed seaward as it moves downstream along the coast (Chapman and Lentz, 1994). This offshore progression with increasing latitude is evident in Figs. 8 and 9a, and is a feature of the majority of images analysed. During the summer, the dynamics of the bottom part of the plume will be most strongly influenced by near-bed processes, while the surface-advected part, decoupled from the bottom, is affected by surface processes such as Coriolis and wind stress. Once released from the influence of bottom stress the surface front can progress much further offshore and occupies a wider range of positions. Evidence of the surface and bottom fronts behaving in different ways is found 
in Fig. 12a where the bottom front moves shoreward and the surface front advances offshore. This is likely the result of enhanced estuarine circulation that can occur during neap tides (Geyer et al, 2000). Intensified westward surface residuals are compensated at depth by eastward near-bed flows that subsequently drive the shoreward retreat of the bottom front.

Salinity, rather than temperature, is the primary control on stratification in Liverpool Bay (Palmer, 2009). The limitations of using SST as an indicator of the fronts' position should therefore be considered. Between May and August the salinity and temperature structures contribute equally to the vertical density distribution (Czitrom and Simpson, 1998), and CEFAS SmartBuoy data shows temperature and salinity to be significantly negatively correlated during the summer months. For example, during July 2007 the correlation coefficient for the raw 30 minute time series is -0.8 , significant at the $99 \%$ level. From this perspective, satellite SST images during the summer should be representative of the fronts location. Conversely, at the interface between the ROFI and the wider Irish Sea, where salinities are higher, the water column may seasonally stratify if currents are weak enough (Howarth and Palmer, 2011). This makes the separation of warm, fresh plume water from warm, saline Irish Sea water less reliable and introduces a westward bias to the estimated position of the surface front. It is difficult to know what contribution any seasonal thermal stratification may be making to the summertime neap position in Fig. 8a. Analysis of model density does not suffer from this complication.

Sea surface temperatures during the winter revealed less spring-neap movement $(5-10 \mathrm{~km})$ than during the summer $(25-30 \mathrm{~km})$. This is supported by the model and explained by increased summer buoyancy and decoupling of the surface and bottom fronts. The higher probability of finding winter spring fronts further offshore however can not be fully explained (Fig. 8b). It is unclear whether this unexpected finding is the result of dynamically different regimes, or simply a consequence of the composite presentation of results. Larger and more frequent periods of stratification and frontal movement take place during the summer which are more readily identified against shorter timescale variability. Over the winter, flood-ebb advection and the irregular response to wind stress and river discharge may mask more subtle fortnightly adjustments to tidal mixing energy when five years worth of data are combined.

Fortnightly stratification and remixing over large areas of Liverpool Bay is one of a number of processes responsible for the redistribution of fresh water, the relative importance of each requiring consideration. A weak, but continual background residual circulation comprising northwesterly surface flow and southeasterly near-bed currents (Heaps, 1972), may be enhanced by semidiurnal tidal straining (Simpson et al, 1990; Verspecht et al, 2009b), and therefore make a significant contribution to the horizontal mass flux of fresh water (Jay and Musiak, 1994; Prandle, 2004). Based on five years of observational data Verspecht et al (2009b) estimate the long term mean surface residual at the main observatory mooring site to be $0.025 \mathrm{~m} . \mathrm{s}^{-1}$ (northwesterly). Palmer (2009) reports comparable northward residuals of $0.036 \mathrm{~m} . \mathrm{s}^{-1}, 20 \mathrm{~km}$ further west. 
Using Verspecht et al's (2009b) estimate and the approach introduced in Section 6, we can approximate the contribution that this baroclinic residual may make to the annual export of fresh water out of Liverpool Bay. Considering a $0.025 \mathrm{~m} . \mathrm{s}^{-1}$ residual flow across a $5 \mathrm{~m}$ deep surface layer, over a $10 \mathrm{~km}$ east-west section, then $3.9 \times 10^{10} \mathrm{~m}^{3} \mathrm{yr}^{-1}$ is advected northwards through this layer. If $8 \%$ of this total volume is considered to be fresh (where $S_{f}=10$ ), then $3.15 \times 10^{9} \mathrm{~m}^{3} \mathrm{yr}^{-1}$ of estuarine discharge is exported by the residual flow. This accounts for approximately $43 \%$ of the total model estuarine inflow. In comparaison to the $19 \%$ from post-neap stratification and spring remixing, the residual circulation makes the more substantial contribution toward fresh water export.

Although the slow residual circulation may be responsible for the majority of fresh water export, spring-neap tidal mixing and the associated frontal movement can influence biogeochemical cycles within Liverpool Bay. During the winter, between December and February, there is a strong linear relationship between the primary nutrient concentrations and salinity (Greenwood et al, this issue). The main source of nutrients is from river inputs and during the winter their distribution is principally controlled by the physical mixing of fresh and saline waters within the ROFI. Greenwood et al (this issue) show that the mean ( \pm 1 standard error) monthly concentration of TOxN (nitrite + nitrate) across the observatory survey grid is highest in February $(18 \pm 1 \mu \mathrm{mol}$ $\left.\mathrm{l}^{-1}\right)$. This is coincident with a regime of surface-advected plumes and enduring stratification (Fig. 10). Taking a TOxN concentration within the surface plume to be $18 \mu \mathrm{mol} \mathrm{l}^{-1}\left(252 \mathrm{mg} \cdot \mathrm{m}^{-3}\right)$, over a depth of $5 \mathrm{~m}$, when stratification is eroded $1260 \mathrm{mg} \cdot \mathrm{m}^{-2} \mathrm{TOxN}$ is lost from the plume. Over the 7 days between neap and spring tides this is an irreversible export rate of $180 \mathrm{mg} \cdot \mathrm{m}^{-2}$.day ${ }^{-1}$. For a $20 \mathrm{~km}$ stretch of front, adjusting by $10 \mathrm{~km}, 252$ tonnes TOxN (or 36 tonnes.day $^{-1}$ ) is mixed out of the plume. During late winter therefore when a wide area of the bay stratifies, for example between days 20 and 30 in 2007 (Fig. 10), large amounts of nutrients can be mixed out of surface waters.

Over the summer months nutrient concentrations are much lower and the salinity-nutrient relationship is not so conservative. Following wintertime accumulation, rapid biological uptake during the spring bloom depletes the nutrient pool and the system becomes net autotrophic (Greenwood et al, this issue; Panton et al, this issue). Fortnightly cycles in chlorophyll- $a$ concentration and dissolved oxygen saturation suggest that spring-neap variability in tidal mixing has a role to play in controlling biological cycles through its influence on sediment and nutrient resuspension from the bed and the associated impact on light penetration (Panton et al, this issue). The area over which this takes place i.e. the scale of frontal adjustment, will be reflected in the scale of any phytoplankton blooms, which are visible in ocean colour satellite imagery. 


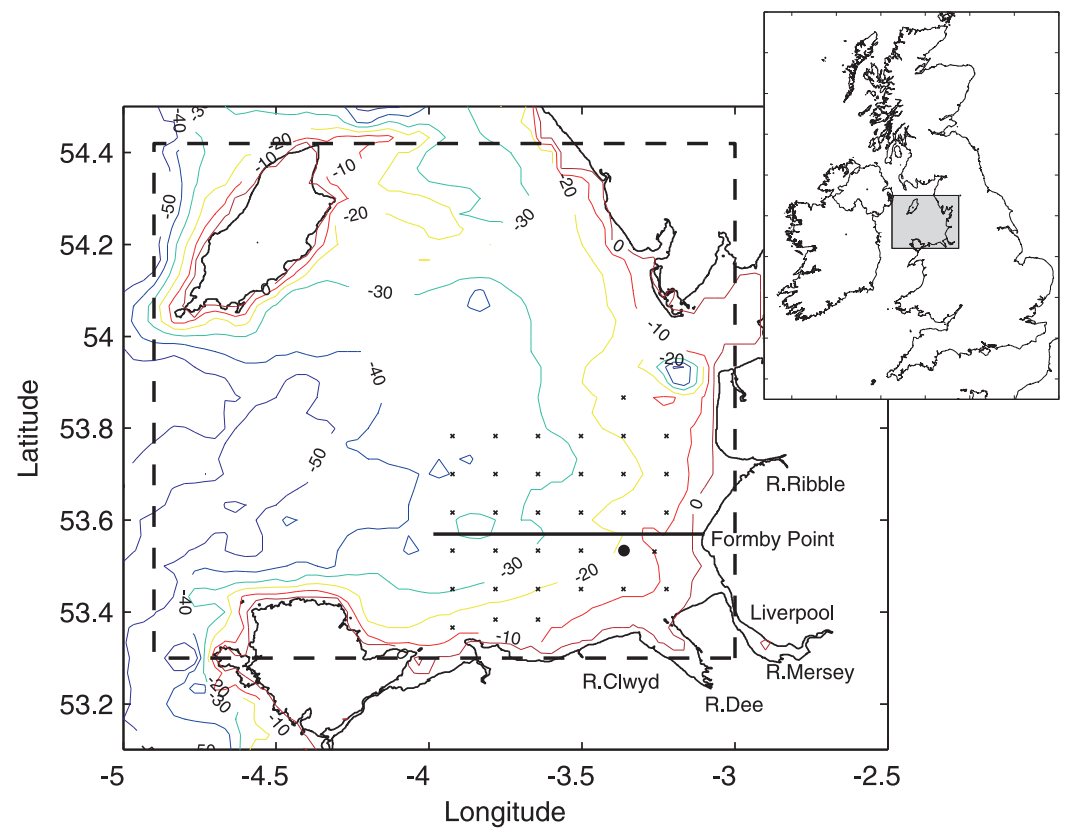

Fig. 1 The Eastern Irish Sea and Liverpool Bay. Contours are depth (m). Black circle marks the location of the ISO main mooring site. CTD stations are indicated by small black crosses. The dashed box shows the area of each SST image that was analysed. The horizontal line extending from Formby Point marks the location of the model transect. 
a. 02-May-2007 22:20:00

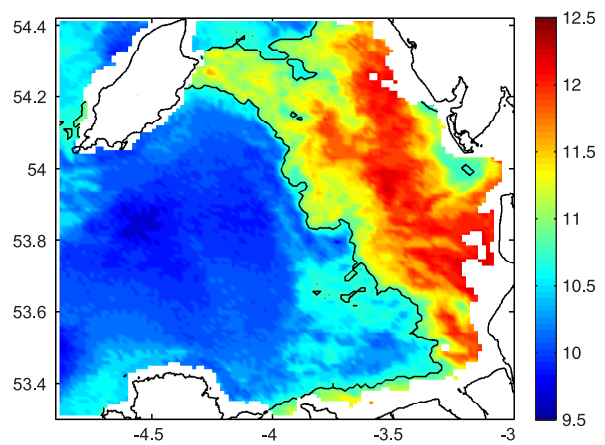

c. 07-Apr-2007 02:03:00

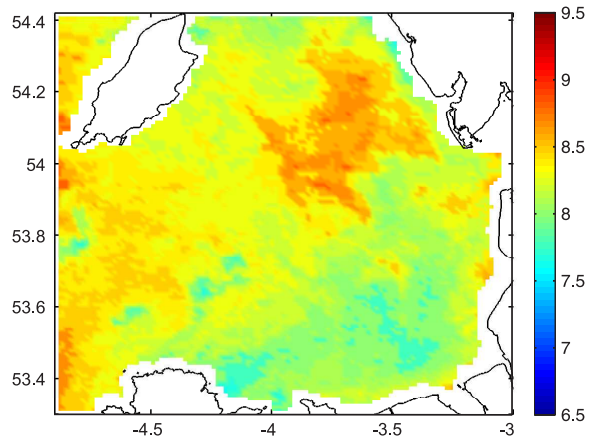

b. 22-Aug-2007 20:45:00

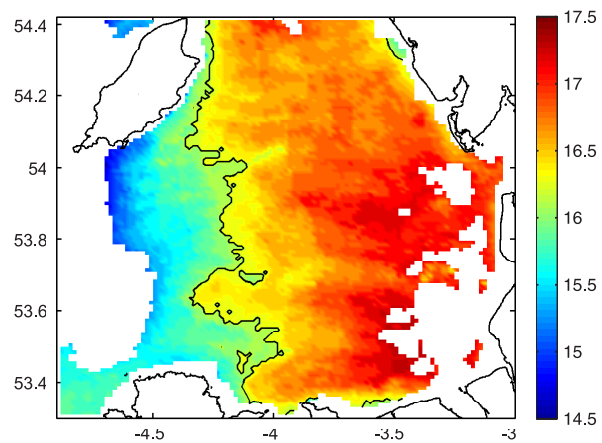

d. 22-Jan-2007 10:46:00

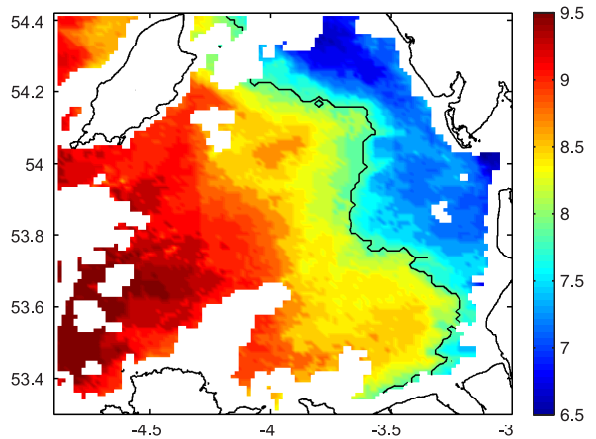

Fig. 2 Satellite SST images of the thermohaline front and freshwater plume at different times of the year. Black contours mark the position of the front as estimated using the mixture modelling technique described in Section 3. All colorbars have a range of $3^{\circ} \mathrm{C}$. 
a. Unimodal distribution

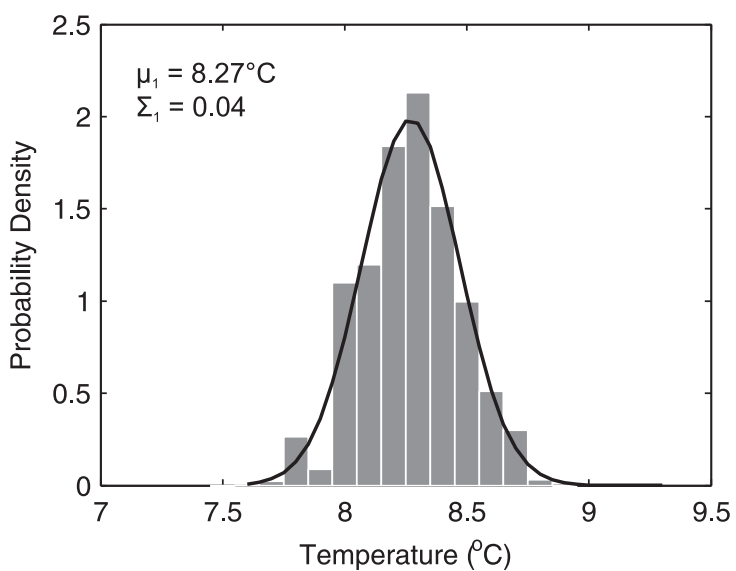

b. Bimodal distribution

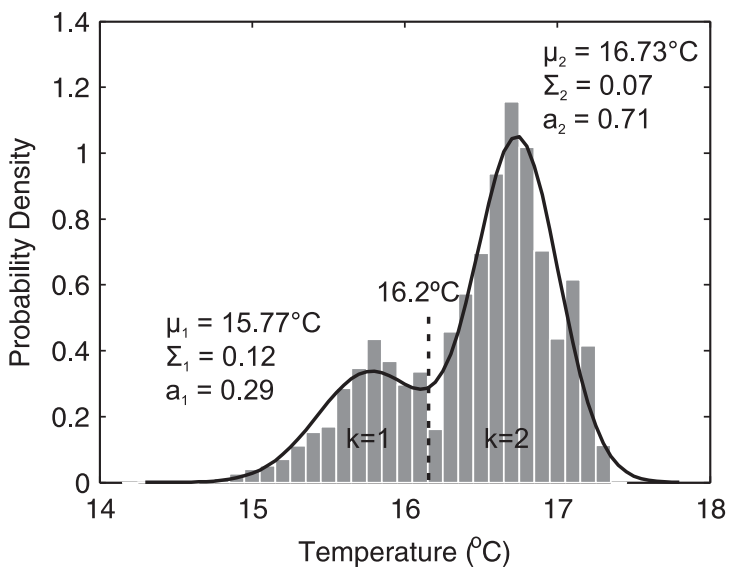

Fig. 3 The probability density functions of SST observations on a. $7^{\text {th }}$ April 2007 02:03:00 (Fig. 2c) where only one water mass can be distinguished, and b. $22^{\text {nd }}$ August 2007 20:45:00 (Fig. 2b) where the distribution is bimodal. The dashed line marks the $16.2^{\circ} \mathrm{C}$ isotherm optimally separating the two water masses. $\mu$ and $\Sigma$ are the means and variances of each water mass respectively. $\mathrm{a}_{1}$ and $\mathrm{a}_{2}$ are proportions of the total number of observations assigned to each water mass. 


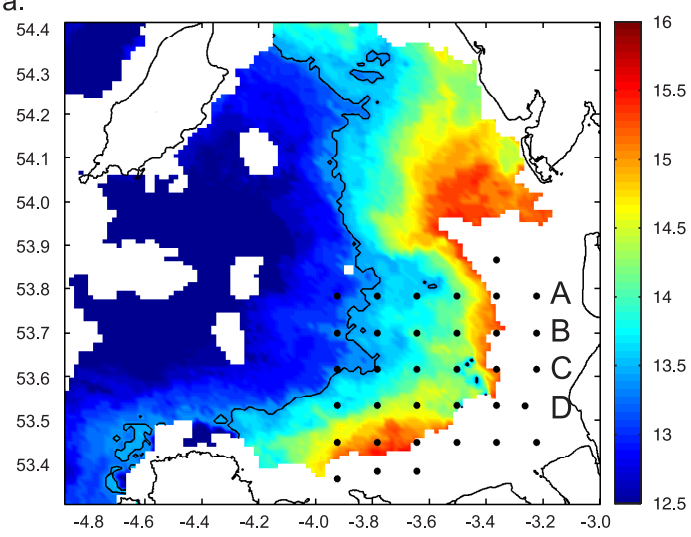

b.
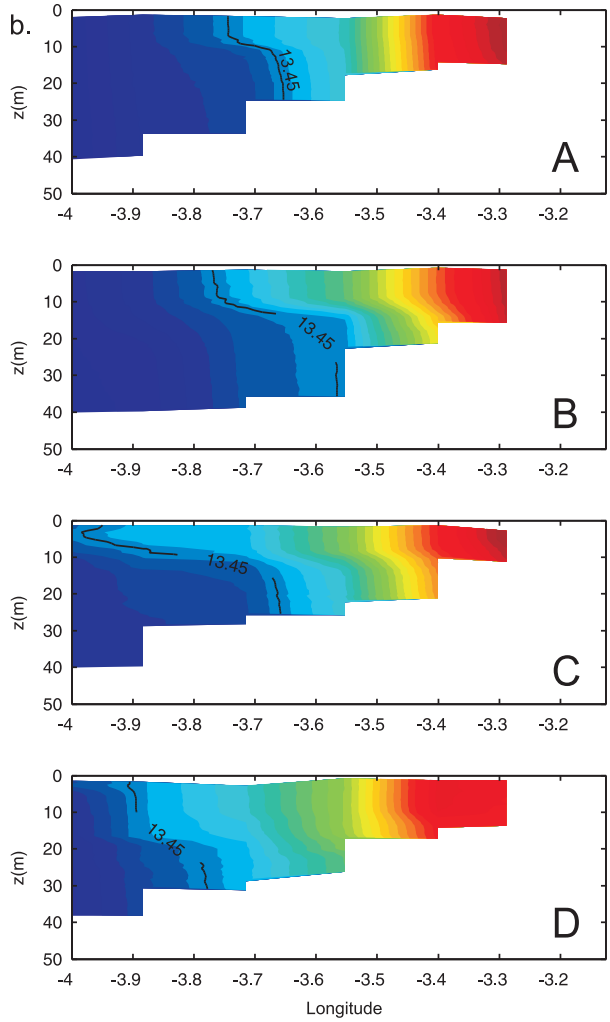

Fig. 4 a. Satellite image of SST $\left({ }^{\circ} \mathrm{C}\right)$ on $20^{\text {th }}$ June 2007 at 21:40:00. The black contour marks the estimated position of the front $\left(13.45^{\circ} \mathrm{C}\right.$ isotherm). Black dots are the locations of CTD casts. b. Longitude-depth transects (marked A-D in a.) of the temperature taken between $20^{\text {th }}$ and $21^{\text {st }}$ June 2007 . The $13.45^{\circ} \mathrm{C}$ contour as estimated from a. is marked. 


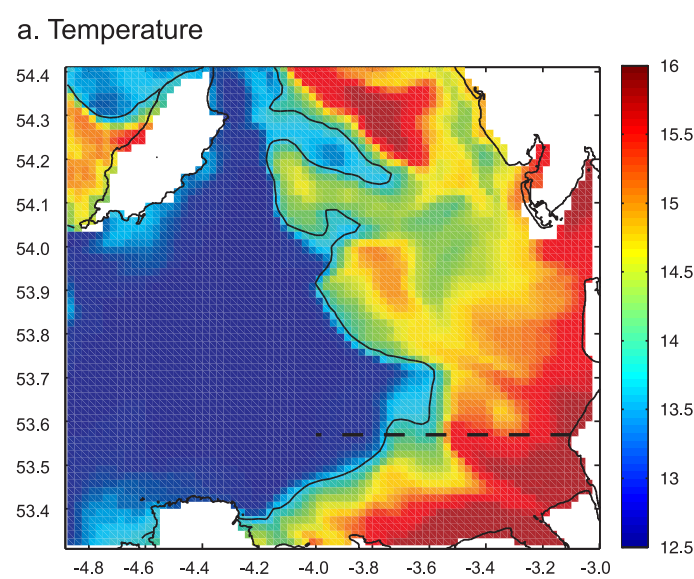

b. Temperature

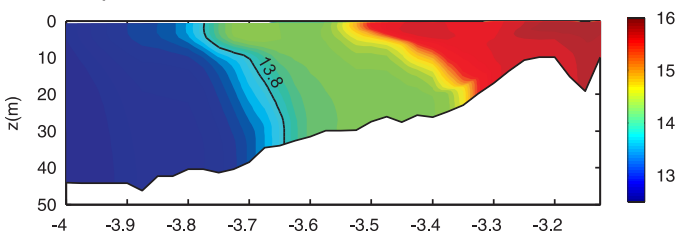

c. Salinity

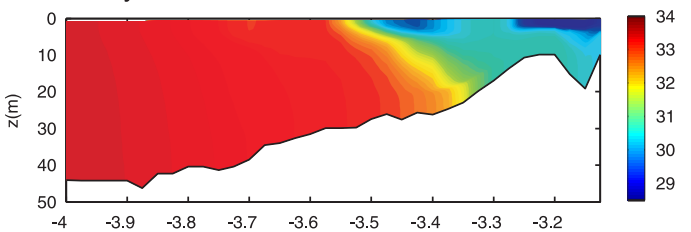

\section{d. Density SURFACE FRONT}

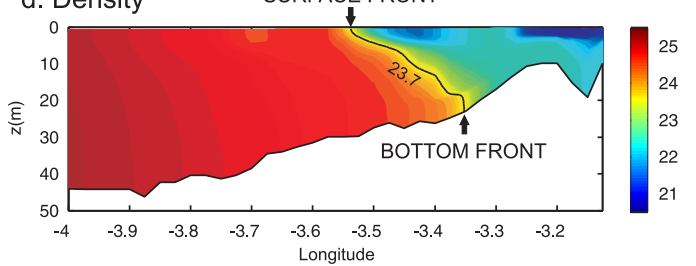

Fig. 5 Model output on $20^{\text {th }}$ June 2007 21:40:00. a. Surface temperature field. The black contour $\left(13.8^{\circ} \mathrm{C}\right)$ marks the estimated position of the front using this SST field. Dashed line marks the location of the transect. b-d. Temperature, salinity and density transects. The $13.8^{\circ} \mathrm{C}$ contour in b. marks the fronts' location as estimated from the SST values in a. and is a comparison to Fig. 4. The black contour in d. shows the position of the front estimated using the depth-longitude density field. 

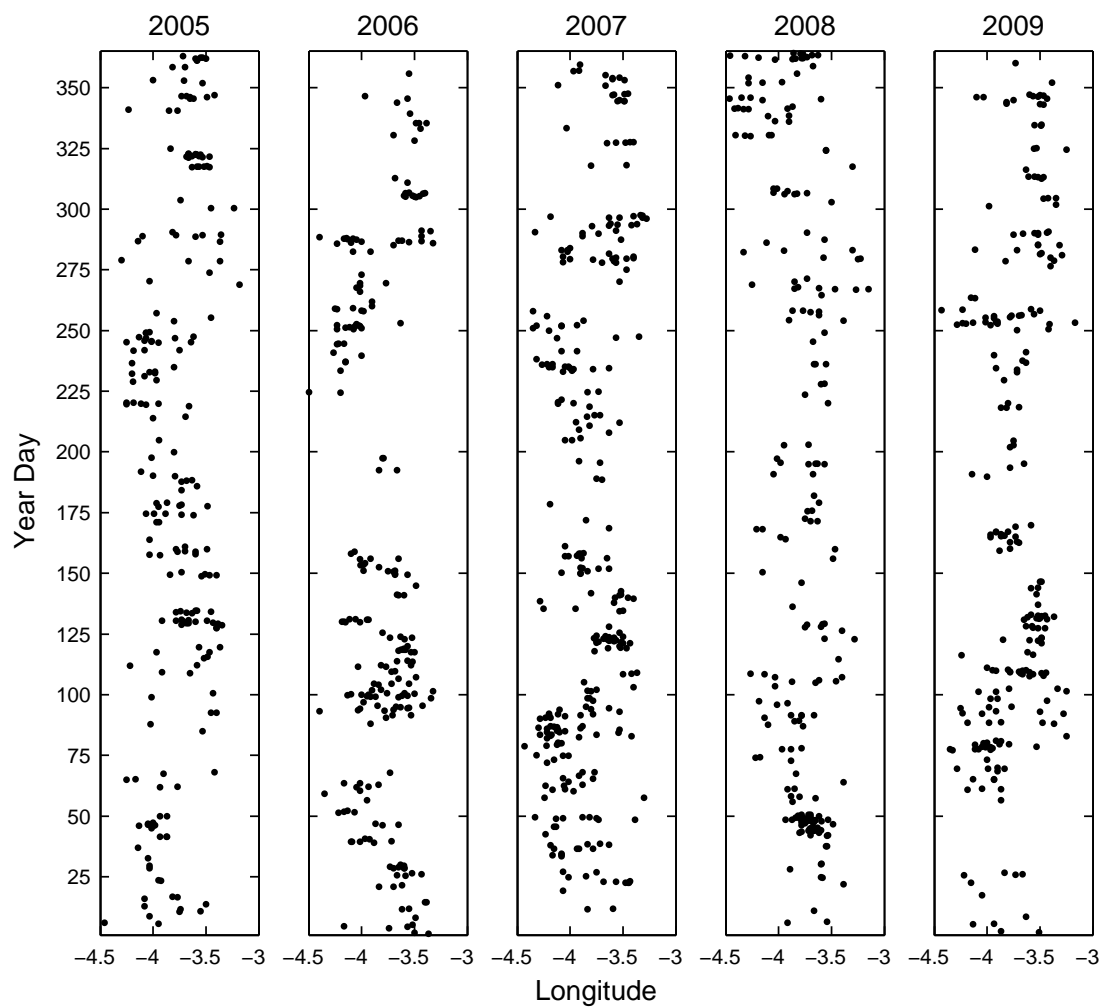

Fig. 6 Median frontal location (longitude) between $53.5-54^{\circ} \mathrm{N}$ estimated from each SST image. 


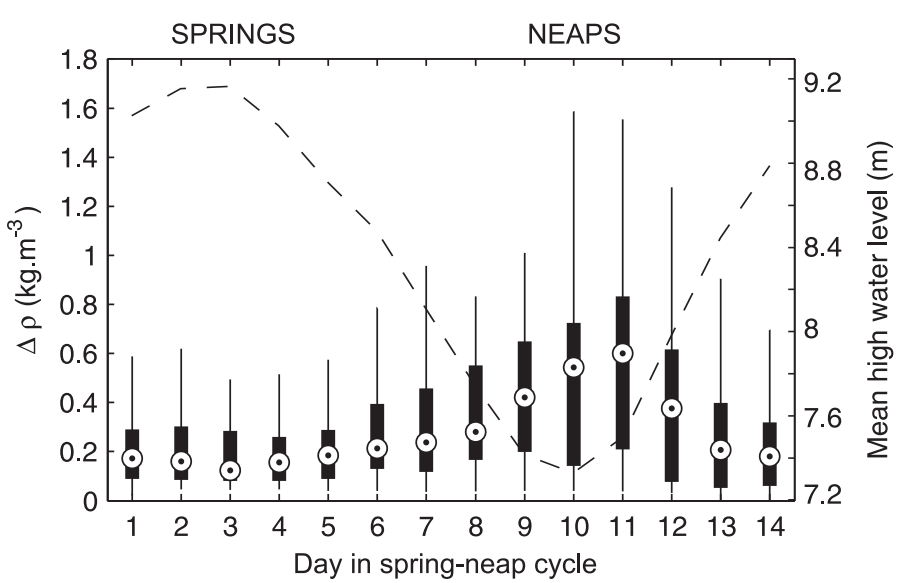

Fig. 7 Density anomaly between the bottom and $5 \mathrm{~m}$ at the main observatory mooring site (27 $7^{\text {th }}$ July 2006 to $27^{\text {th }}$ July 2007 ), classified according to the day of the spring-neap cycle. Open circles mark the median density anomaly. Filled boxes extend between the upper and lower quartile ranges. Whiskers extend to the most extreme values within 1.5 times the interquartile range. The dashed black line is the mean high water level over the same period at Gladstone Dock, Liverpool, relative to the Lowest Astronomical Tide. 
a. Summer

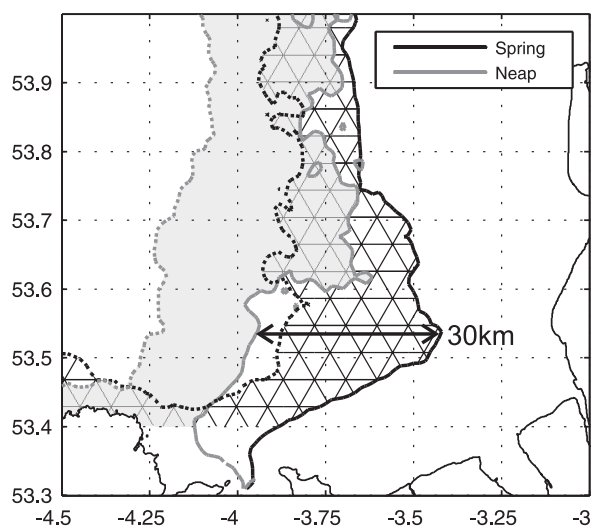

b. Winter

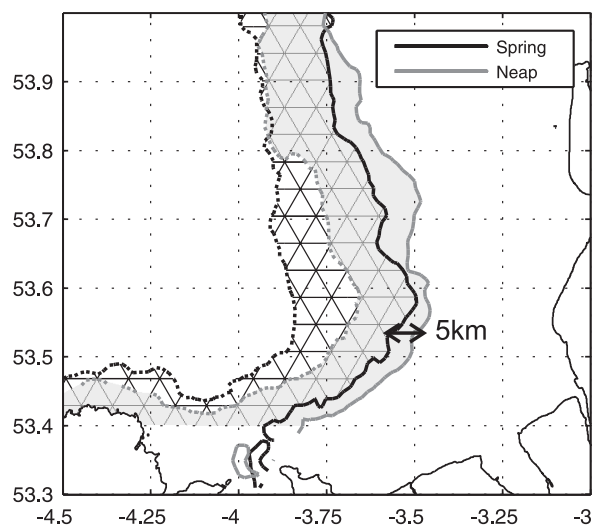

Fig. 8 The $99 \%$ (solid lines) and $1 \%$ (dashed lines) confidence contours during neap (days 3 4) and spring (days 10-11) tides. The shaded and hashed areas in-between represent the most probable region for the front to be found in during neap and spring periods respectively. a. Summer neaps $(\mathrm{N}=76)$ and springs $(\mathrm{N}=96)$. b. Winter neaps $(\mathrm{N}=100)$ and springs $(\mathrm{N}=79)$. $\mathrm{N}$ refers to the number of SST images within each category. 
a.

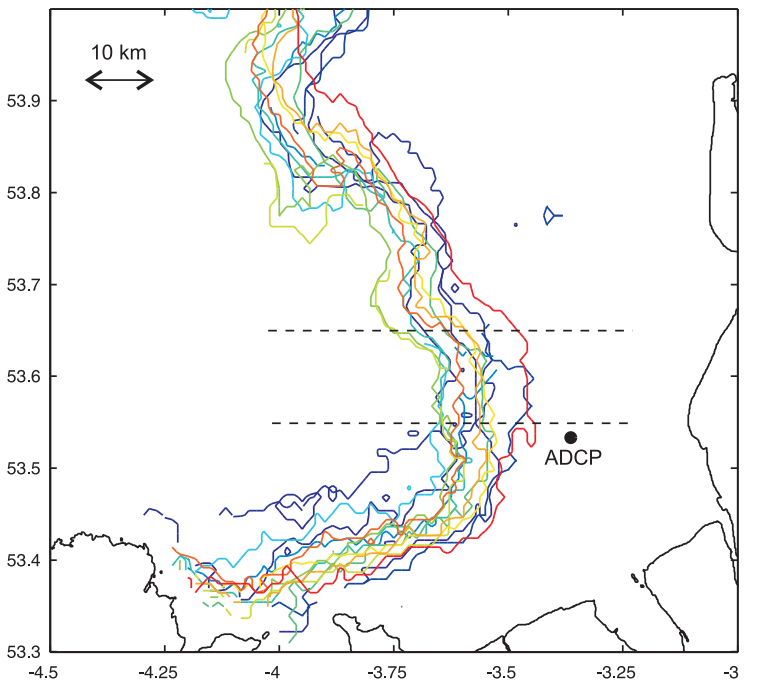

b. $u\left(m . s^{-1}\right)$

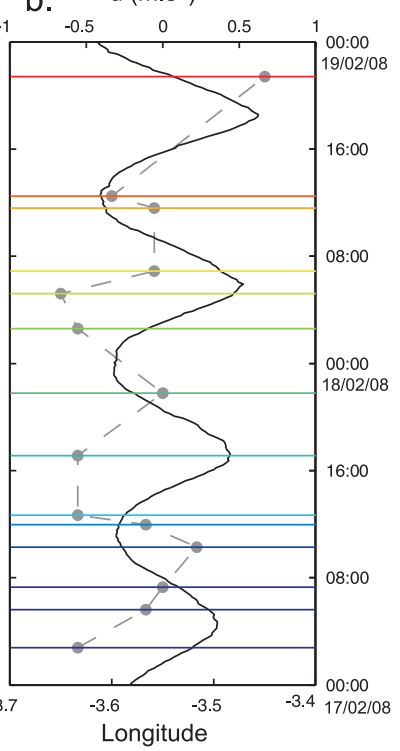

Fig. 9 a. Estimated position of the front from individual SST images between the $17^{\text {th }}$ and $18^{\text {th }}$ February 2008. b. Median frontal location between $53.55-53.65^{\circ} \mathrm{W}$ (dashed line and circles), and depth mean east-west velocity $\left( \pm \mathbf{u} \mathrm{m} . \mathrm{s}^{-1}\right)$ from ADCP measurements (solid black line). Exact times of each estimate are indicated by the horizontal lines. 

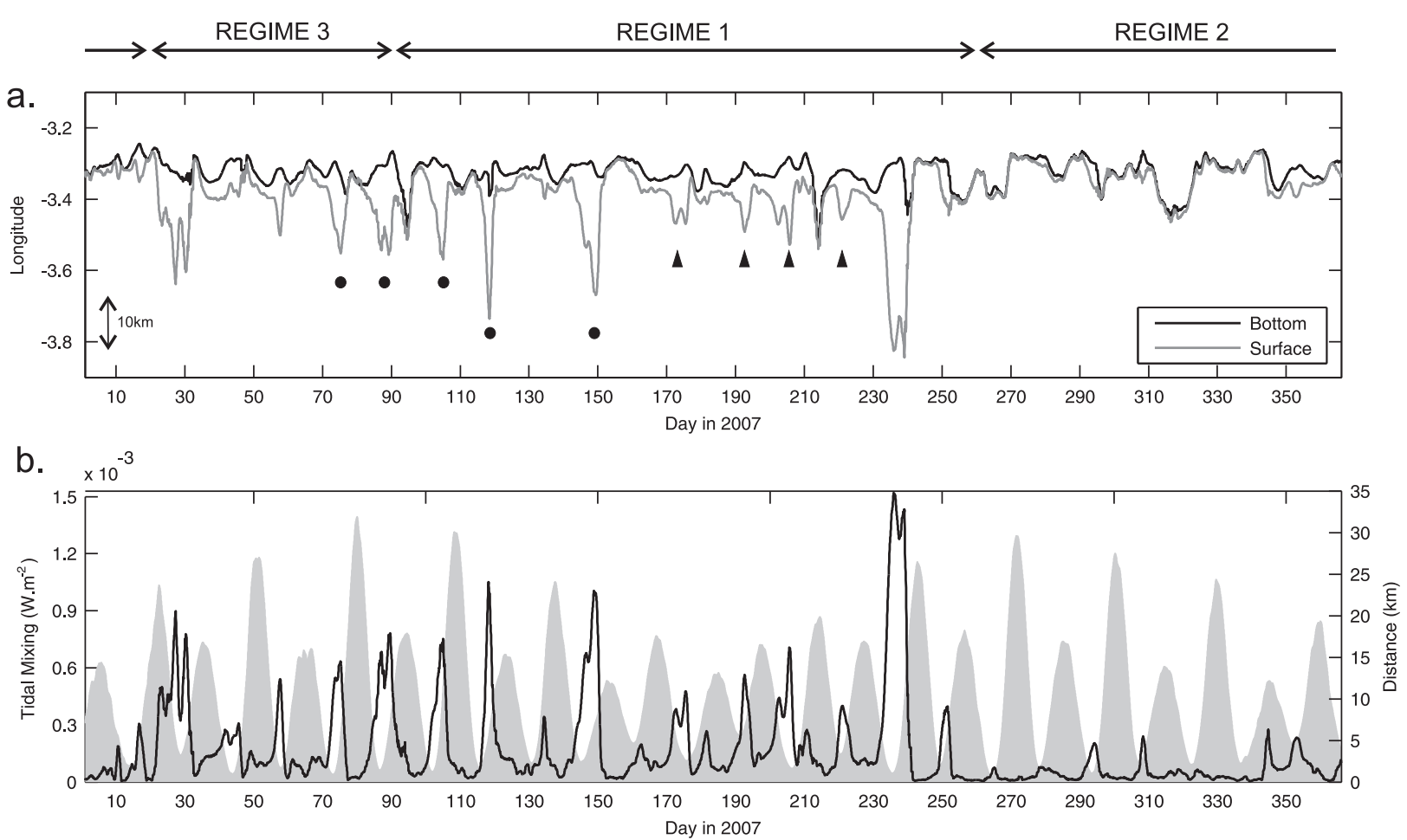

Fig. 10 a. Location of the surface front and bottom re-attachment over the model year (smoothed with a 25 hour filter to remove semi-diurnal variability). Circles and triangles indicate events referred to in the text. b. Distance $(\mathrm{km})$ between the surface and bottom fronts indicating the extent of stratification (black line), and the tidal mixing power (gray shading). Tidal mixing $=\epsilon \kappa_{b} \rho\left\langle\mathbf{u}^{3}\right\rangle$ at $3.4^{\circ} \mathrm{W}$ and is fully defined in the text. 

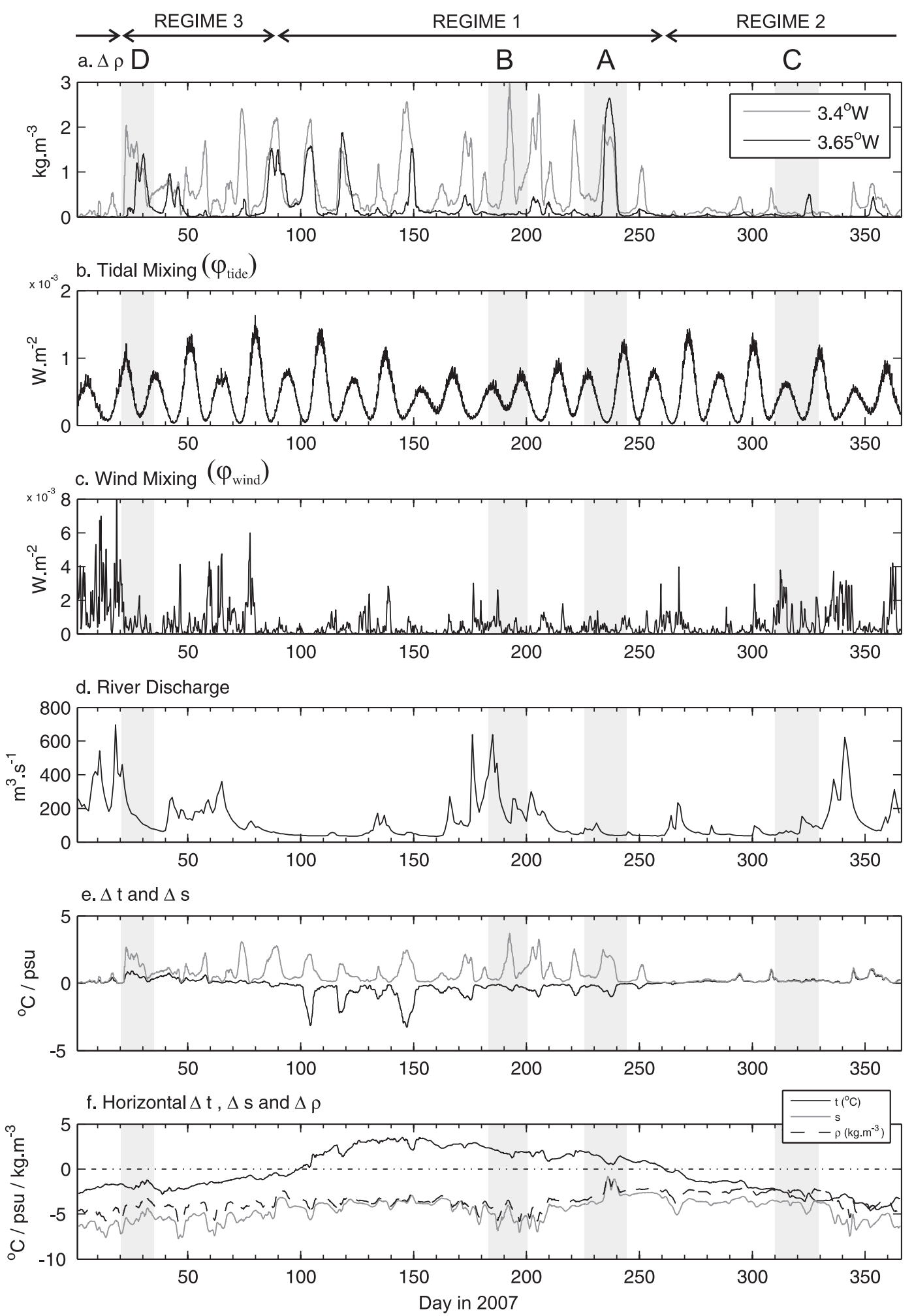

Fig. 11 a. Top-bottom density difference $(\Delta \rho)$ at $3.4^{\circ} \mathrm{W}$ and $3.65^{\circ} \mathrm{W}$. b. Tidal mixing $\left(\varphi_{\text {tide }}\right)$ at $3.4^{\circ} \mathrm{W}$. c. Wind mixing $\left(\varphi_{\text {wind }}\right)$. d. Total river discharge from the Mersey and Dee catchments $\left(\mathrm{m}^{3} \cdot \mathrm{s}^{-1}\right)$. e. $\Delta t$ and $\Delta s$ at $3.4^{\circ}$. f. Horizontal $\Delta t, \Delta s$ and $\Delta \rho$ between $3.125^{\circ} \mathrm{W}$ and $4^{\circ} \mathrm{W}$. Note that the series in a, e and $\mathrm{f}$ have been smoothed with a 25 hour filter window. 
a. Event $A$

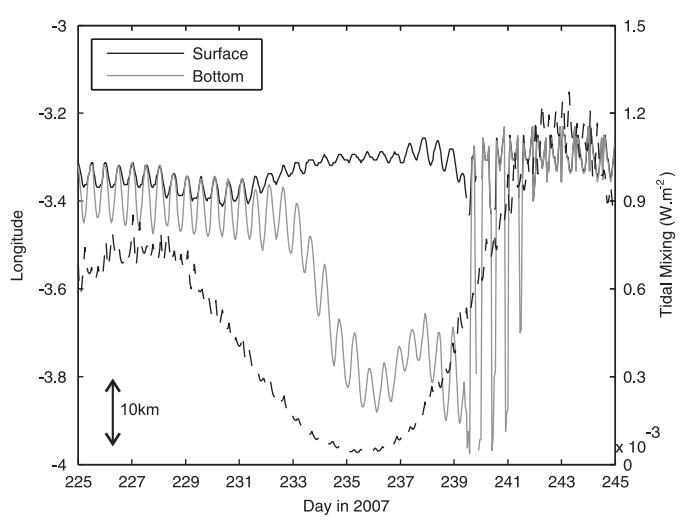

c. Event C

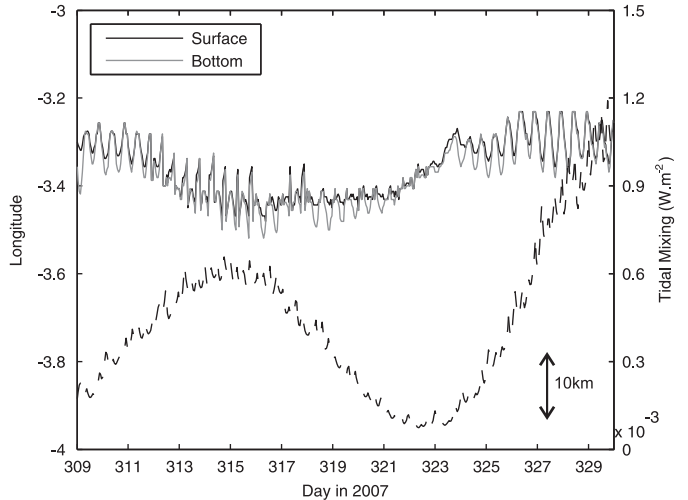

b. Event B

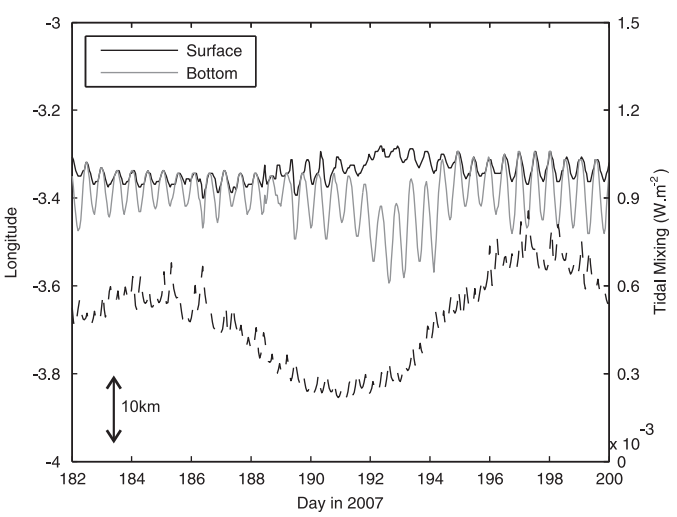

d. Event D

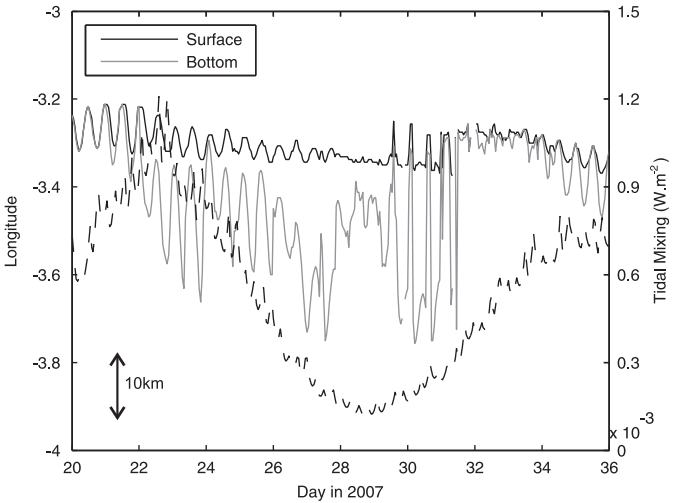

Fig. 12 Location of surface and bottom fronts during events A to D (solid gray and black lines respectively), and the tidal mixing power (dashed black line). 


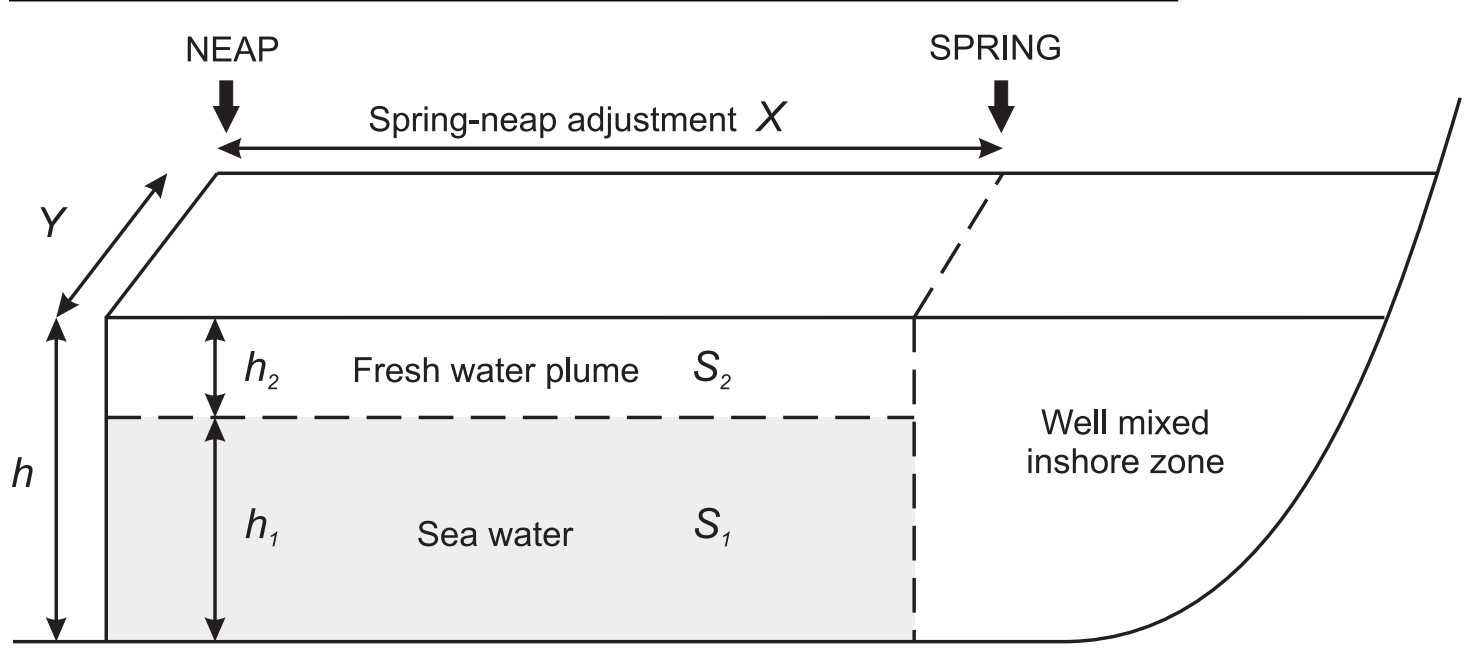

Fig. 13 Schematic showing spring-neap adjustment of a surface advected plume. 
Acknowledgements All remote sensing data was provided courtesy of the NERC Earth Observation Data Acquisition and Analysis Service, Plymouth (http://www.neodaas.ac.uk/). We thank all those involved with the Irish Sea Observatory who have collected and processed the data sets used in this study. The authors are grateful for the constructive comments and suggestions made by two anonymous reviewers that have improved this manuscript. 


\section{References}

Balfour C, Howarth MJ, Smithson M, Jones D, Pugh J (2007) The use of ships of opportunity for Irish Sea based oceanographic measurements. In: Marine challenges: coastline to deep sea, Aberdeen, Scotland, Oceans '07 IEEE Aberdeen, p 6

Burchard H (2009) Combined effects of wind, tide, and horizontal density gradients on stratification in estuaries and coastal seas. J Phys Oceanogr $39(9): 2117-2136$

Burchard H, Flöser G, Staneva J, Riethmuller R, Badewien T (2008) Impact of density gradients on net sediment transport into the Wadden Sea. J Phys Oceanogr 38:566-587

Canuto V, Howard A, Cheng Y, Dubovikov M (2001) Ocean turbulence. Part I: One- point closure model - momentum and heat vertical diffusivities. J Phys Oceanogr 31(6):1413-1426

Cayula JF, Cornillon P (1992) Edge-detection algorithm for SST images. J Atmos Oceanic Technol 9(1):67-80

CEH (2007) Derivation of daily outflows from Hydrometric Areas. Internal report, CEH Wallingford. July 2003.

Chapman DC, Lentz S (1994) Trapping of a coastal density front by the bottom boundary layer. J Phys Oceanogr 24:1464-1479

Czitrom SPR, Simpson JH (1998) Intermittent stability and frontogenesis in an area influenced by land runoff. J Geophys Res Oceans 103(C5):10,369 10,376

Geyer W, Cannon G (1982) Sill Processes Related to Deep Water Renewal in a Fjord. J Geophys Res Oceans 87(C10):7985-7996

Geyer W, Trowbridge J, Bowen M (2000) The Dynamics of a Partially Mixed Estuary. J Phys Oceanogr 30:2035-2048

Greenwood N, Hydes D, Mahaffey C, Wither A, Barry J, Sivyer D, Pearce D, Hartman S, Andres O, Lees H (this issue) Spatial and temporal variability in nutrient concentrations in Liverpool Bay, a temperate latitude region of freshwater influence. Ocean Dyn

Hastie T, Tibshirani R, Friedman J (2001) The Elements of Statistical Learning: Data Mining, Inference, and Prediction. Springer Series In Statistics, Springer-Verlag, New York

Heaps N (1972) Estimation of density currents in the Liverpool Bay area of the Irish Sea. Geophys J Roy Astronom Soc 30:415-432

Holt J, James ID (1999) A simulation of the Southern North Sea in comparison with measurements from the North Sea Project. Part I: Temperature,. Cont Shelf Res 19:1087-1112

Holt J, James ID (2001) An s-coordinate density evolving model of the north west European continental shelf. Part 1 Model description and density structure. J Geophys Res Oceans 106(C7):14,015-14,034

Holt J, James ID (2006) An assessment of the fine-scale eddies in a highresolution model of the shelf seas west of Great Britain. Ocean Mod 13:271291 
Holt J, Proctor R (2008) The seasonal circulation and volume transport on the northwest European continental shelf: A fine-resolution model study. J Geophys Res 113, C06021 DOI:10.1029/2006JC004034

Holt J, Umlauf L (2008) Modelling the tidal mixing fronts and seasonal stratification of the Northwest European Continental shelf. Cont Shelf Res 28:887903

Holt J, Allen J, Proctor R, Gilbert F (2005) Error quantification of a highresolution coupled hydrodynamic-ecosystem coastal-ocean model: Part 1 model overview and assessment of the hydrodynamics. J Mar Syst 57:167188

Howarth MJ, Palmer MR (2011) The Liverpool Bay Coastal Observatory. Ocean Dyn (Accepted), DOI: 10.1007/s10236-011-0458-8

James ID (1996) Advection schemes for shelf-sea models. J Mar Syst 8:237-254

Jay D, Musiak J (1994) Particle trapping in estuarine tidal flows. J Geophys Res Oceans 99(C10):20,445-20,461

Linden PF, Simpson JE (1988a) Gravity-driven flows in a turbulent fluid. J Fluid Mech 172:481-497

Linden PF, Simpson JE (1988b) Modulated mixing and frontogenesis in shallow seas and estuaries. Cont Shelf Res 8(10):1107-1127

Miller P (2009) Composite front maps for improved visibility of dynamic seasurface features on cloudy SeaWiFS and AVHRR data. J Mar Syst 78:327336

Monismith S, Burau J, Stacey M (1996) Stratification dynamics and gravitational circulation in northern San Francisco Bay. In: Hollibaugh T (ed) San Francisco Bay: The Ecosystem, Pacific Division, Amer. Assoc. Adv. Sci., pp $123-153$

Nunes R, Lennon G (1987) Episodic stratification and gravity currents in a marine environment of modulated turbulence. J Geophys Res 92(C5):54655480

Palmer MR (2009) The modification of current ellipses by stratification in the Liverpool Bay ROFI. Ocean Dyn 60(2):219-226

Panton A, Montagnes D, Sharples J, Hopkins J, Mahaffey C (this issue) Shortterm and seasonal variation in metabolic balance in Liverpool Bay. Ocean Dyn

Polton J, Palmer MR, Howarth MJ (2011) Physical and dynamical oceanography of Liverpool Bay. Ocean Dyn (Accepted), DOI: 10.1007/s10236-0110431-6

Prandle D (2004) Saline intrusion in partially mixed estuaries. Estuarine Coastal Shelf Sci 59:385-397

Ruddick K, Deleersnijder E, Luyten P, Ozer J (1995) Haline stratification in the Rhine-Meuse fresh water plume: a three-dimensional model sensitivity analysis. Cont Shelf Res 15:12,507-12,630

Scully M, Friedrichs C (2007) The importance of tidal and lateral asymmetries in stratification to residual circulation in partially mixed estuaries. J Phys Oceanogr 37:1496-1511 
Sharples J, Simpson JH (1993) Periodic frontogenesis in a region of fresh-water influence. Estuaries 16(1):74-82

Sharples J, Simpson JH (1995) Semi-diurnal and longer period stability cycles in the Liverpool region of freshwater influence. Cont Shelf Res 15(2-3):295313

Shimada T, Sakaida F, Kawamura H, Okumura T (2005) Application of an edge detection method to satellite images for distinguishing sea surface temperature fronts near the Japanese coast. Remote Sens Environ 98(1):21-34

Simpson JH, Bowers D (1981) Models of stratification and frontal movement in shelf seas. Deep-Sea Res Part A- Oceanogr Res Papers 28(7):727-738

Simpson JH, Brown J, Matthews J, Allen G (1990) Tidal straining, density currents, and stirring in the control of estuarine stratification. Estuaries $13(2): 125-132$

Simpson JH, Sharples J, Rippeth TP (1991) A prescriptive model of stratification induced by fresh-water runoff. Estuarine Coastal Shelf Sci 33(1):23-35

Unesco (1981) The practical salinity scale 1978 and the international equation of state of seawater 1980. Tenth report of the Joint Panel on Oceanographic Tables and standards. Unesco technical papers in marine science 36 . Tech. rep., Sponsored by UNESCO, ICES, SCOR, IAPSO

Verspecht F, Rippeth TP, Howarth MJ, Souza AJ, Simpson JH, Burchard $\mathrm{H}$ (2009a) Processes impacting on stratification in a region of freshwater influence: Application to Liverpool Bay. J Geophys Res Oceans 114, C11022, DOI:10.1029/2009JC005475

Verspecht F, Rippeth TP, Simpson JH, Souza AJ, Burchard H, Howarth MJ (2009b) Residual circulation and stratification in the Liverpool Bay region of freshwater influence. Ocean Dyn 59(5):765-779

Vincent M, Atkins S, Lumb C, Golding N, Lieberknecht L, Webster M (2004) Marine Nature Conservation Development- the Irish Sea Pilot. Report to Defra by the Joint Nature Conservation Committee, Peterborough

Yankovsky AE, Chapman DC (1997) A simple theory for the fate of buoyant coastal discharges. J Phys Oceanogr 27(7):1386-1401 